\title{
Implementation of Digital Technologies into Pre-Service Mathematics Teacher Preparation
}

\author{
Mária Slavíčková
}

check for updates

Citation: Slavíčková, M. Implementation of Digital Technologies into Pre-Service Mathematics Teacher Preparation. Mathematics 2021, 9, 1319. https:// doi.org/10.3390/math9121319

Academic Editors: Jarmila Novotná, Alena Hošpesová and David Pugalee

Received: 15 April 2021

Accepted: 4 June 2021

Published: 8 June 2021

Publisher's Note: MDPI stays neutral with regard to jurisdictional claims in published maps and institutional affiliations.

Copyright: (C) 2021 by the author. Licensee MDPI, Basel, Switzerland. This article is an open access article distributed under the terms and conditions of the Creative Commons Attribution (CC BY) license (https:/ / creativecommons.org/licenses/by/ $4.0 /)$.
Department of Didactics in Mathematics, Physics and Informatics, Faculty of Mathematics, Physics and Informatics, Comenius University in Bratislava, 84248 Bratislava, Slovakia; slavickova@fmph.uniba.sk

\begin{abstract}
This paper presents a long-term study of Preservice Mathematics Teachers (PMTs) at the Faculty of mathematics, physics and informatics, Comenius University in Bratislava (FMFI UK), focusing on the implementation of digital technologies (DT) into the teaching of theoretical and practical (or applied) subjects. We conducted parallel research into two aspects, one on Calculus lessons as a theoretical subject, another on the Financial Mathematics module as an applied subject. The implementation of DT and the way this was measured varied from year to year and also in the method of implementation into the aforementioned subjects. The methods of implementation and the results are briefly described, and a comparison of these two subjects in the PMTs' preparation is also discussed.
\end{abstract}

Keywords: preservice mathematics teachers; digital technology; calculus; financial mathematics

\section{Introduction}

The implementation of digital technologies (DT) into the teaching and learning process of mathematics started at the end of the 20th century. The environments for dynamic geometry, the computer algebra system and graphic calculators were the main areas in which research was conducted. Several researchers have pointed out how DT could overcome the limitations of paper and pencil, e.g., [1,2] while others have focused on the preparation of prospective Mathematics teachers (PMTs), e.g., [3,4].

The use of DT differs and can be beneficial in many aspects. As [5] (pp. 20-21) declared, the teaching and learning process provides an environment in which DT is a tool for communication, cooperation, or both. Ernst and Ryan [6] (p. 222) stated that "tools are the materials, models and representations that students use to organize and keep track of their thinking as they solve problems". Cohen and Hollebrands [7] stated the importance of encouraging synchronous (for, e.g., blogs) and asynchronous (for, e.g., wikis) collaboration, communication and the construction of knowledge in the classroom. Jančařík and Novotná [8] designed mathematical problems for higher secondary students where the computer algebra system (CAS) could be beneficial in reaching the solution, by either modelling the solution numerically or by using the computational power of computers. Hoyles and Lagrange [9] discussed

" ( . . ) how far studies have taken on board the challenges of the use of digital technologies and their potential for the improvement of mathematics teaching, learning and the curriculum, remains a matter of debate". [9] (p. 2)

Gruson et al. [10] when comparing two case studies-English and Mathematics teachers-observed significant use of digital resources in both cases, but of a different nature. In our study we compare two cases as well: the teaching and learning process in Theoretical as well as Applied mathematics.

In our own research, the target area was the use of modelling and visualization processes in different digital environments. Following a review of the relevant literature and the impact of the Covid-19 pandemic, there is no doubt that further research in this area is crucial, a notion confirmed for example in [11]. 
We can identify two main threads in the research concerning the implementation of DT in mathematics education at the university level. Firstly, research focused on theoretical mathematics (such as Calculus, Algebra, etc.). In our research we have focused on Calculus due to our professional interest. Secondly, research focused on applied mathematics (such as Financial Mathematics, Management, Economy, etc). Due to the educational reforms in Slovakia in 2008, we focused on Financial Mathematics since it has become an integral part of mathematics education in Slovakia, starting at lower secondary school. As the research we conducted covered two distinct strands, the text is organised as follows: firstly, the strand concerning Calculus and, secondly, the strand concerning Financial Mathematics (FM). Our study aims to compare different approaches in implementing DT into the aforementioned types of Mathematics lessons. We will briefly review the results in both areas-Calculus and Financial mathematics.

\subsection{Theoretical Subject in Preparation PMTs}

Research connected to understanding theoretical concepts in Calculus is usually focused on different topics (like sequences, limits, derivatives, integrals, etc.). We looked only at the research aimed at the limit concept, the reason being that the concept of a limit is fundamental to the standard foundation of other aspects of Calculus. Williams [12] discovered that observations by teachers are corroborated in empirical research that documents the extreme difficulty in using a formal limit as a foundation for teaching calculus. Guin and Trouche [13] showed the influence of the representation of the situation on graphic calculators in finding a limit of the function. This research showed that graphic calculators are often the most influential tool for investigation and, in some cases, the only one. Cottrill et al. [14] argued limit as a complex schema with two important processes: process of $x$ approaching to the given point and the process of $f(x)$ approaching to $L$. Tall et al. [15] recognized that students had difficulties seeing sequences as a cognitive whole; for example, sequence $a_{n}=\left\{\begin{array}{c}1+\frac{1}{n}, n=2 k \\ \frac{1}{n}, n=2 k+1\end{array}\right.$. McDonald et al. [16] examined students' cognitive construction of the concept of sequence.

The mainstream of our research concerning calculus was (and still is) on the concept of the limit of a sequence. The focus on " $\varepsilon-\mathrm{n}_{0}$ " definition of a limit of the sequence was described in [17], using of "epsilon strip" in [18]. We used the aforementioned "epsilon strip" approach to make sense of arbitrary epsilon and its relationship to $\mathrm{n}_{0}$ in defining a limit of a sequence. Later, when introducing the limit of a function, similarly to Arganbright [19], we used spreadsheets to explore the "epsilon-delta" definition of a limit of a function. Chappell and Killpatrick [20] investigated the effects of the instructional environment (concept-based vs. procedure-based) on students' conceptual understanding and procedural knowledge of calculus. The latter led us to study not only procedural knowledge but the level of understanding. The targeted group was PMTs studying for their bachelor's degree.

Later studies have continued in the implementation of DT using different approaches. Swinyard [21] made students write computer code for sequence $x_{n}$ approaching the given real number and then examine the sequence $f\left(x_{n}\right)$. While we found this approach not applicable to our group, but it was an inspiration for the preparation of small software environments for PMTs. Jones [22] focused on students' understanding of limits at infinity or infinite limits that involve continuous functions (as opposed to discrete sequences). We implemented this kind of task in PMTs preparation and also into the tests. Pinto and Scheiner [23] investigated how mathematics university students understood the limit concept of a sequence. Fernández-Plaza and Simpson [24] explored how students linked different basic limit concepts. As the literature review on this stage of research shows, there are minimal steps forward in finding the best way of how to work with a limit concept properly and avoid PMTs misconception. Therefore, in this strand of our research, we (1) tried to use good practices described and tested in the researchers mentioned above, and (2) prepare innovative lessons by using a computer with mathematical software. 


\subsection{An Applied Mathematics in Preparation of PMTs}

The second strand of our research was focused on FM. Bernheim et al. [25] integrated instructions on topics related to household financial decision-making in higher education. They provided systematic evidence of the long-term behavioural effects. They reported "significantly increased exposure to financial education, and ultimately elevated the rates at which individuals save and accumulate wealth during their adult lives" (p. 462). Avard et al. [26] assessed the financial literacy of 407 first-year students, reporting an average of $34.8 \%$ correct responses. When preparing the 1st module of FM in 2008/2009 which was to be implemented into the PMTs' preparation at FMFI UK, we made it based on the recommendations of OECD [27] and implemented the topics crucial as a result of the literature review in PMTs' preparation. In later studies, Vankúš [28] suggested using interactive Excel sheets in modelling/solving mathematical tasks from FM. Chong et al. [29] studied the technological integration approach of teaching and learning FM on a sample of 85 undergraduates. They found out a significant impact of DT on the research sample. Drábeková and Švecová [30] dealt with the insufficient financial literacy of first-year students at the university. Fajkus [31] discussed the relationship between mathematical symbols, economic terms and real-life terminology in the environment of Mathematica. Rosaker and Rosaker [32] conducted a study of Master of Business Administration (MBA) students and found that a parsed approach to teaching financial literacy, as opposed to a single personal finance course, represented a potentially effective method for addressing their basic financial literacy needs. Rosa and Petrášková [33] developed an original collection of educational materials with the use of the CAS Maple to support the financial education of PMTs. Lopes and Soares [34] implemented a flipped model into courses of Financial Mathematics with a positive impact on a sample of over 800 students within three years. All of the aforementioned studies indicated the importance of the research in the area of FM and looking for the best way of implementation of DT into students (and in some cases like $[30,33]$ PMTs) preparation.

\subsection{Rationale and Aims}

Even though there are several subjects where PMTs can focus on presenting different kinds of software, most of our PTMs do not consider it to be applicable in their future career (based on the results of an internal evaluation of the educational process by students, held every examination period during the year). On the other hand, PMTs struggle with theoretical subjects such as Calculus, Algebra, etc. and consider these to be too abstract and with little connection to school mathematics (based on the aforementioned results from the internal evaluation). To demonstrate to our PMT's the usefulness of both technology and theoretical subjects we decided to implement digital technologies into a course of Calculus $[35,36]$. Later, we also implemented DT into didactical seminars where FM has its place $[37,38]$ We wanted to know how the implementation DT into theoretical and applied mathematics differs and what there is in common. Therefore, this paper has two main parts. The first one is focused on the implementation of DT into Calculus as one of the theoretical subjects in the preparation of PMTs (research commenced in 2008), and the second part is focused on the implementation of DT into FM, which can be characterized as a subject with the application of mathematical content (research commenced in 2009).

Modelling through the use of DT and symbolization on the blackboard (or in the notebook) following classroom discussions are key mechanisms for developing content knowledge and technological-content knowledge of pre-service mathematics teachers. Our goal is to make them use the aforementioned mechanisms in their work (as in-service teachers). It is this specific goal which is the primary focus of this paper. We will briefly describe the results of the aforementioned studies and discuss the results of our research.

\section{Theoretical Framework}

There are several theoretical frameworks in papers concerning the implementation of DT into mathematics. Several researchers used Microworlds and Constructionism [39,40]. 
We can find the Process-Object theoretical framework, e.g., [41-44]. A different approach to Visual and Analytical thinking can be identified in other studies, e.g., [45,46]. Mostly in French didactics it is the use of the Theory of didactical situation, the concept of milieu, e.g., $[47,48]$.

We are using the framework of TPACK as introduced by Mishra and Koehler [49] which describes the kinds of knowledge needed by a teacher for the effective integration of technology. There are three main competencies in the TPACK model: Technological knowledge (TK), Content knowledge (CK) and Pedagogical knowledge (PK). TPACK is one of four competencies that address how these three main bodies interact (see also Figure 1). TPACK was proposed as the interconnection and intersection of TK, CK and PK.

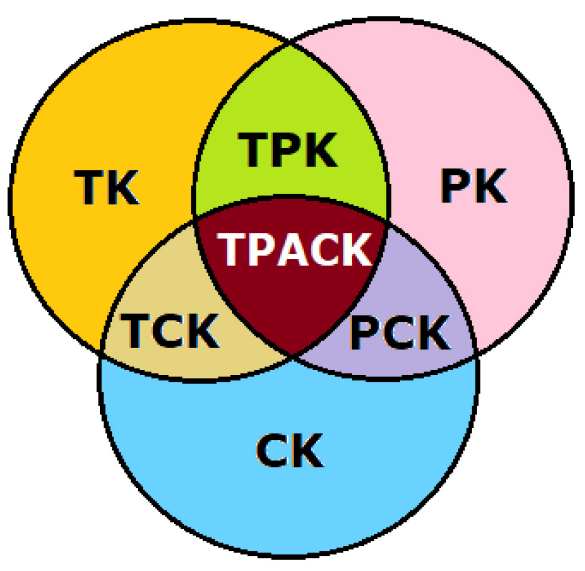

Figure 1. TPACK model, authors' representation.

Our research has focused on two components of the TPACK model. The first component is Technological-Content knowledge (TCK) which refers to "knowledge of the reciprocal relationship between technology and content. Disciplinary knowledge is often defined and constrained by technologies and their representational and functional capabilities." [50] (p. 102). The second component is Technological, pedagogical and content knowledge (TPACK) which "refers to knowledge about the complex relationships between technology, pedagogy and content that enable teachers to develop appropriate and context-specific teaching strategies" (ibid)

Koehler et al. [50] identified three paths in the development of TPACK in PMTs: (a) from PCK to TPACK, (b) from TPK to TPACK and (c) developing PCK and TPACK simultaneously. In our research we focused on a path which Koehlers' et al. did not mention in their work: from TCK to TPACK. We did so because integrating the functionalities of different representation in the CAS system (such as graphical, numerical and/or formal computation) does not necessarily facilitate conceptualization [51] (this issue, p. 8)

Ball et al. [52] distinguish three competencies in CK which they termed Subject Matter Knowledge (SMK):

- Common content knowledge (CCK), defined as "the mathematical knowledge and skill used in settings other than teaching" (p. 13), which includes the teachers' need to know and understand the material they teach, their ability to recognise students' wrong answers or to identify any inaccuracies in the textbook, etc.

- Specialized content knowledge (SCK), defined as "the mathematical knowledge and skill unique to teaching" (p. 14), which includes looking for and recognising patterns in student errors, non-standard approaches, whether a given solution would work in general, etc.

- Horizon content knowledge, defined as an "awareness of how mathematical topics are related over the span of Mathematics included in the curriculum" (p. 17), which includes being able to see connections to more advanced mathematical ideas. 
In the research presented later in the text we used several theoretical frameworks within the TPACK-Dubinsky's APOS theory [43], Brousseau's Theory of didactical situations [53] and Ernest's social constructivism approach [54]. In the following text, we provide a brief reminder of the terms we are operating within as per the description of our research. Since the presented results of this paper are focused mostly on the level of PMTs knowledge, we explain APOS theory in this place a bit more than the other mentioned theories.

Since APOS distinguishes four levels of knowledge (Action, Process, Object and Schema [43]), it offers a tool for measuring the level of CK or understanding. As Dubinsky and McDonald [55] defined, an action is a transformation of objects by the individual as external and requiring step-by-step instructions on how to perform the operation. By reflecting on an action, the individual can interiorize the action and form an internal mental construction called a process. In the process the individual can perform and describe the transformation without external stimuli. An object is constructed when the individual encapsulates the process as a totality and can now perform transformations on this process. Finally, a schema is an individual's collection of actions, processes, objects and other schemas that are linked by some general principals to form a coherent framework in the individual's mind.

There are different types of didactic situations distinguished in Brousseau's TDS [53]. The first three are part of the a-didactic situation (auto didactic situation, not a "nondidactic" situation). In the Situation of action, the teacher organizes a milieu for the students. Knowledge appears as a means for solving a problem or a class of problems. Sierpinska, [56] (p. 4) In the Situation of formulation, students exchange and compare observations between themselves. They may not have the language to formulate their observations, so their main effort in this situation goes into creating such a language and agreeing on some common meanings (p. 3). In the Situation of verification, students try to explain some phenomenon or to verify a theoretical conjecture. The teacher acts as the chair of a scientific debate (ibid). In the Situation of institutionalization, the teacher informs the students about the officially accepted terminology, definitions, theorems considered important from the institution's points of view (ibid).

Before the teaching unit an a priori analysis is made. The a priori analysis can be characterized as an explanatory model of students' and teachers' behaviour. Its goal is to identify potential obstacles, misconceptions, mistakes, corrections and further work with these mistakes. In this analysis, prerequisite knowledge necessary for the use of the different solving strategies are essential. After the teaching unit, an a posteriori analysis is made. In the a posteriori analysis, the a priori analysis is compared with experience from the realized teaching unit in the classroom, and recommendations for changes are formulated.

TDS could be a strong tool for the analysis of situations in the classroom. Its use within the TPACK model could help explain both students' and teacher's behaviour. That was the reason for choosing this framework in the description of PMTs.

As briefly presented above, TPACK could be used with different theoretical frameworks to obtain a deeper insight into the situations in the classroom (or lessons). The choice of the theory to be linked with the TPACK model relies on the purpose of the study and a research question.

\section{Methodology and Sample Description}

The research included several groups of PMTs in their 1st and 4th years of studying to become Mathematics teachers. The sample size differed from phase-to-phase depending on the actual size of the groups of PMTs studying at FMFI UK. Since this article presents outputs of longitudinal research in two strands, the specific numbers of PMTs were determined at the beginning of each research phase.

The overall methodology of the early stages of research involved a didactical experiment: enter test, determination of experimental and control group, tests and comparison of the collected data. This was not possible to attain in later stages of the study due to 
organizational changes at FMFI UK. Therefore, the later stage (Sections 4.2, 5.2 and 5.3) design differs. We choose a pre-test and post-test design, in other words working with one group and looking for PMTs progress (comparing pre- and post-tests).

In both designs, we applied supportive methods of collecting data:

- Structured observations of PMTs progress on CCK and SCK (when PMTs solved the tasks on blackboard or into their notebooks)

- Group interviews concerning CK, TK and TCK (after the tests)

- Questionnaire concerning real-life experiences (used in the last stage of the research)

The collected data helped us to formulate conclusions and answer stated research questions. Data processing from earlier stages provided entry points for the formulation of new research questions for the next phase of our research.

In every phase of our research, we used DT in several ways. First, for the visualization of different processes (like a limit of a sequence, financial growth, etc.). Second as a smart calculator (finding the result of specific limit, annuity, etc.). Third, for communication between PMTs and between PMTs and the teacher (mostly asynchronous, using LMS Moodle). When solving the tests, PMTs were not allowed to use DT.

Tests were scored using the levels of APOS (Section 4.1) or in \% (the other phases), then hypothesis were tested by means of a statistical method appropriate to the particular size of the groups. Specific methods are introduced at the beginning of each phase of the research.

\section{Implementation DT into Theoretical Subject-Development of Technological-Content Knowledge (TCK)}

In this part we focus on the implementation of DT into courses of mathematical analysis. From the literature review and our teaching experiences, we decided to implement DT into the preparation of the Calculus lessons for PMTs. There are several studies concerning differential or integral Calculus (e.g., [57,58]). Research concerning the use of digital technologies usually has the same structure: a comparison of the procedural abilities between the experimental and control group (in other words, a group taught with digital technologies and a group taught without digital technologies) $[20,59,60]$. Several studies declare that infinity (or concept of limit) is extremely difficult for students [61-63] and understanding is rare among the students in the first two years of university studies. We have followed this pattern in the $1^{\text {st }}$ phase of our research concerning the PMTs' skills [18]. In the second phase, we focused on the durability of the PMTs' knowledge [36]. The second phase was specific by also leading lectures (not only exercises) from mathematical analysis. These studies were followed by other studies [64-66] in which any newly raised questions were answered.

There were two reasons for the implementation of DT into teaching CK. First, we wanted to demonstrate to the students that DT could help them visualize the situation and construct abstract knowledge. Second, we hypothesized that if students experience teaching new concepts by using DT, they will be more open to using it in their future teaching career. Results from the study opened up new questions which we have been researching in the following phases of the research. Nowadays, PMTs have 3 semesters of Calculus (the functions of 2 real variables were moved to the master study as a voluntary subject). The other difference is that we have now moved the Calculus from the 1st semester to the 3rd semester.

The PMTs encountered the aforementioned concepts in the first semester of their Bachelor's degree to be a secondary school Mathematics teacher. The PMTs had 4 semesters of Calculus; each semester focused on a different main topic. Semester 1: limits and derivatives; semester 2: series; semester 3: integrals; semester 4: functions of 2 real variables. Our research sample comprised PMTs in the first study at the University. The focus was on their knowledge/understanding of the limit concept in the first semester.

The research concerning TCK which started in 2008 is still in progress. We will describe the first 3 phases of this research and their results as well as suggestions for further research 
in this area. There is also a new phase of the research that had to be modified due to the COVID-19 situation. At the end we will briefly summarize the modification and the first observations of its pros and cons.

\subsection{The 1st Phase}

In the first phase of the research, we focused on the PMTs' understanding of a function, properties and graph, followed later on in the semester by a focus on the limit of a sequence and a function, a derivative of a function. Our hypothesis was that students who used DT in their preparation would have a better insight into the limit concept than the students who did not used DT in their preparation. We decided to use the software Graphic Calculus (more information and link for download: https: / / www.vusoft.eu/GraphicCalculus.htm (accessed on 8 June 2021)) which is suitable for users of different ages, levels of mathematical knowledge and skills with DT as well. For less advanced users/pupils in mathematics doing modules like finding a formula, graphing, parabola, line etc., Graphic Calculus provides a vital aid in the visualization and conceptualization of mathematical concepts. For more advanced users such university students of mathematics, derivative, integrals, Taylor polynomial, etc., Graphic Calculus is a more dynamic source of visualization. Users can adjust the speed of visualization (step-by-step, or varying the speed of animation), view a table of values and other expressions of the same phenomena. Since the author of Graphic Calculus declared that the "program should especially benefit starting students" [67], we have found it especially suitable for PMTs in the first semester of their study at university.

We encouraged PMTs to use DT for the class exercises and at home by giving them extra tasks in order to earn extra points. There is a free demo version (in the time of writing this paper, Graphic Calculus was not working under the OS Win10) of Graphic Calculus with full functionality of all the concepts we were focused on in the study. In the lessons (or home preparation), PMTs could use DT to search and analyse information obtained concerning the main topic of an exercise (for, e.g., motivation, additional information, usability in other subjects outside the mathematics, etc.) All the results were discussed and clarified with the group of students.

To find out the answers for our research questions we took a group of 12 PMTs and divided them into groups of 6 students in each according to the test results. We picked the experimental group randomly due to the equivalent score in the test of both groups of PMTs. The author of this article taught both groups using different methods. In the experimental group, she prepared materials requiring Graphic Calculus as well as questions concerning what could be observed using DT. For the control group, the same set of tasks were used but without the use of DT. The topic and order of the tasks was the same for both groups.

The experimental group spent more time with visualization, exploration and conceptualizing the concept of a limit and, later, the derivative of a function. The time for solving tasks "by hand" was shorter compared to the control group. The control group had the same organization of exercises as the experimental group but instead of working with DT and making their own conclusions from observations, the teacher explained the concepts on the blackboard (usually by using colour chalk). Then the PMTs in control group focused on the procedure of finding a limit of the sequence/function and, later, the derivative of the function.

We assigned students some notebooks and tablets courtesy of the Hewlet-Packard project "Application of mobile technology in preparation of future mathematics teachers". We got 20 tablets and notebooks, which the PMTs used for modelling, visualization, observation, etc. It took a long time for the PMTs to get familiar with Graphic Calculus in order to get to the point where they could not rely on the teacher's help and were able to do own their observations. The teacher used a projector to show students how to use the software and encouraged them to discover other mathematical properties in groups and to explain them to the others. The level of digital literacy was not the same in the group. There were 2 PMTs who were unhappy to be in the DT-taught group and had what amounted to a phobia of working with computers. However, when paired with someone 
more skilled, they were able to help with drawing conclusions from the activities. Once PMTs became familiar with the technology side, the lessons started to be more dynamic and we observed more mathematical discussions compared to the control group.

During the semester we prepared 2 tests for both groups in two versions. The versions differed only in constants and/or coefficients. We wanted to keep the principle (or idea of solving) the same and have an opportunity to collect comparable data. The 1st test was written in the middle of the semester and contained only tasks concerning a limit of a sequence (all 6 tasks). The 2nd test was written at the end of the semester and contained tasks for a limit of the function (tasks 1-3) and derivative of the function (tasks 4-6). The PMTs could not use the DT for the solutions. We looked for the levels of knowledge according to Dubinsky's APOS theory [56] (Tables 1-6) and evaluated the tests quantitatively. We did it by assigning weights for each level of APOS (see Table 7) and used them as entry values to find the levels of students' knowledge and the median of the groups' score (Figures 2-7). Then we used a comparison of these scores to validate our assumption concerning the PMTs knowledge levels in the topic of a limit of sequence and function within APOS theory.

The tasks in the tests ranged from the very basic level (for the PMTs' knowledge at the Action level) to the more complex, up to the level of Object or Schema.

Table 1. Task 1 in the 1 st test.

\begin{tabular}{cc}
\hline 1st Group & 2nd Group \\
\hline $\lim _{n \rightarrow \infty}\left(1+\frac{4}{n}\right)^{3}\left(2-\frac{5}{n}\right)^{2}\left(\frac{4}{n}-2\right)^{3}$ & $\lim _{n \rightarrow \infty}\left(2+\frac{3}{n}\right)\left(\frac{5}{n}-4\right)^{2}\left(\frac{2}{n}-1\right)^{3}$ \\
\hline
\end{tabular}

The researcher considered this task as an easy, procedural task to start the test. The reason for including it in the test was to find out the PMTs' ability to correctly use basic theorems of a limit of the product of sequences. Therefore, we only code the first two levels in APOS in this task. The codes to this task were assigned as follow:

- $\mathrm{A}=\mathrm{PMT}$ "stroke out" fractions and multiplied the whole numbers.

- $\quad \mathrm{P}=\mathrm{PMT}$ used the theorem of the limit of the product of sequence and solved the problem.

Table 2. Task 2 in the 1st test.

\begin{tabular}{cc}
\hline 1st Group & 2nd Group \\
\hline $\lim _{n \rightarrow \infty} \sin 2 n \times \frac{10-9 n}{5-n^{2}}$ & $\lim _{n \rightarrow \infty} \sin 2 n \times \frac{7-9 n}{4-n^{2}}$ \\
\hline
\end{tabular}

We include this task in the test to determine whether PMTs can combine knowledge concerning the procedures of finding the limit of the product of two sequences with specific conditions. We apply codes for task 2 as follow:

- $\mathrm{A}=$ application of the procedure for a limit of the quotient (extension of a fraction by $1 / n^{2}$ ), finding the result by using the theorem about the product of boundary sequence and sequence convergent to zero.

- $\quad \mathrm{P}=\sin (2 \mathrm{n})$ is boundary sequence. The fraction converges to zero (the denominator is "stronger"); therefore, the result is zero.

Table 3. Task 3 in the 1st test.

\begin{tabular}{cc}
\hline 1st Group & 2nd Group \\
\hline $\lim _{n \rightarrow \infty}\left(\frac{3 n-2}{1+3 n}\right)^{5 n-3}$ & $\lim _{n \rightarrow \infty}\left(\frac{3 n-2}{1+3 n}\right)^{5 n-3}$ \\
\hline
\end{tabular}

We used this task to determine whether PMTs can distinguish the special sequence that converges to the powers of the Euler's number. We assigned codes to this task as follow: 
- $\mathrm{A}=$ working with the procedure as in task 1 , in this case, " 1 to the anything is 1 ".

- $\mathrm{P}=$ it is Euler number because it is a limit 1 to the infinity.

- $\mathrm{O}=$ it is a power of Euler number, to find out a solution, the modification of the term is needed.

Table 4. Task 4 in the 1st test.

\begin{tabular}{cc}
\hline 1st Group & 2nd Group \\
\hline $\lim _{n \rightarrow \infty} n \times(\sqrt{n-1}-\sqrt{n})$ & $\lim _{n \rightarrow \infty}(\sqrt{(n+a)(n+b)}-n)$ \\
\hline
\end{tabular}

We used this task to find out the PMTs' understanding of infinity and operation with it. Since we were visualizing on the lessons the sequences that subtraction of two infinity does not always lead to zero, we assumed that the experimental group could have fewer misleading ideas when solving this task. Assignment of the codes was as follow:

- $\mathrm{A}=$ direct division of every term in the task by " $\mathrm{n}$ ".

- $\quad \mathrm{P}=$ multiplication of the term by 1 in a specific form (sum of the square roots in the brackets).

- $\mathrm{O}=$ like in a Process, but with correct explanation of the used procedure.

Table 5. Task 5 in the 1st test.

\begin{tabular}{cc}
\hline 1st Group & 2nd Group \\
\hline $\lim _{n \rightarrow \infty} n \times \frac{1^{2}+2^{2}+3^{2}+\ldots+n^{2}}{n^{3}}$ & $\lim _{n \rightarrow \infty} n \times \frac{1^{2}+2^{2}+3^{2}+\ldots+n^{2}}{n^{3}}$ \\
\hline
\end{tabular}

Including a task with an infinite sum in the numerator should determine whether the limit concept is correctly included in PMTs cognitive structure and determine the shift in their understanding of the limit process. Assignment of the codes was as follow:

- $\mathrm{A}=$ division numerator and denominator by $1 / \mathrm{n}^{3}$ (the highest power of " $\mathrm{n}$ " in the fraction), "zero times anything is zero.".

- $\quad \mathrm{P}=$ identification of "infinity times constant," the theorem of a limit of the product of sequence cannot be directly used, using a distributive law in the numerator $\left(1 n+2^{2} n\right.$ $\left.+3^{2} n+\ldots n^{3}\right)$, making the procedure as in Action, the result is 1 .

- $\mathrm{O}=$ finding the general formula for the numerator and procedure follows as in Action level.

- $\quad \mathrm{S}=$ like on an Object level, but after finding the correct sum for the numerator explanation of a result-the sequence diverges to infinity.

Table 6. Task 6 in the 1st test.

\begin{tabular}{cc}
\hline 1st Group & 2nd Group \\
\hline $\lim _{n \rightarrow \infty} \frac{(4 n-2)^{100}(3 n+3)^{200}}{(6 n-5)^{300}}$ & $\lim _{n \rightarrow \infty} \frac{(4 n-2)^{100}(3 n+3)^{200}}{(6 n-5)^{300}}$ \\
\hline
\end{tabular}

The last task of the 1st test should refer to the higher levels on APOS. PMTs who encapsulated several actions and processed them into the objects and schemas should solve this task only "by looking at it". Assignment of the codes was as follow:

- $\quad \mathrm{A}=$ expand the brackets, sometimes without using of binomial theorem (e.g., $(3 n+3)^{200}$ as $(3 n+3)^{2}$ or as $\left.3 n^{2}+9\right)$.

- $\quad \mathrm{P}=$ partial expansion of the terms-using only the highest power of " $\mathrm{n}$ ".

- $\mathrm{O}=$ leading values are powers of terms with " $n$ "; therefore, the limit is the same as the limit of $(4 n)^{100}(3 n)^{200} /(6 n)^{300}$. 
- $\mathrm{S}=$ since the highest power of " $\mathrm{n}$ " is equal in the numerator and denominator, the result is equal to the coefficients with a corresponding power of " $n$ ". Therefore, the result is $(2 \times 3)^{200} / 6^{200}$.

Due to the small size of the groups, we used only a descriptive statistic based on the qualitative analysis of the PMTs' solutions. We prepared a converse table of level of knowledge according to Dubinsky's APOS theory and assigned to them numerical values from the interval $[0,1]$ as follows:

Table 7. Assign values.

\begin{tabular}{cc}
\hline Level in APOS & Numerical Value \\
\hline (none, PMT did not solve the task) & 0 \\
Action & 0.2 \\
Process & 0.6 \\
Object & 0.8 \\
Schema & 1 \\
\hline
\end{tabular}

There is a jump of 0.4 between Action and Process ( 0.2 and 0.6). Since we assumed that several students could be on the Action level but after several cycles within APOS levels, we maintain the value 0.4 to indicate this situation (to be in between $\mathrm{A}$ and $\mathrm{P}$ ).

Then we put weight on each solved task and tried to find which group possessed a higher level of knowledge. The results from both tests and both groups are in Tables 8 and 9 .

Table 8. Results of the 1st test.

\begin{tabular}{|c|c|c|c|c|c|c|c|c|c|c|c|c|c|}
\hline Experimental Group & 1 & 2 & 3 & 4 & 5 & 6 & Control Group & 1 & 2 & 3 & 4 & 5 & 6 \\
\hline Student 1 & 0.2 & 0.6 & 0.6 & 0.6 & 0 & 1 & Student 7 & 0 & 0.2 & 0.2 & 0 & 0 & 0 \\
\hline Student 2 & 0.2 & 0.6 & 0.6 & 0 & 0 & 0 & Student 8 & 0.2 & 0.2 & 0.2 & 0.2 & 0.2 & 0 \\
\hline Student 3 & 0.2 & 0.2 & 0.4 & 0.2 & 0 & 1 & Student 9 & 0.2 & 0.6 & 0.2 & 0.6 & 0.2 & 1 \\
\hline Student 4 & 0.2 & 0.2 & 0 & 0 & 0 & 0 & Student 10 & 0.2 & 0 & 0 & 0.2 & 0 & 0.2 \\
\hline Student 5 & 0.2 & 0.2 & 0 & 0 & 0.2 & 0.8 & Student 11 & 0.2 & 0.2 & 0.6 & 0.6 & 0.2 & 1 \\
\hline Student 6 & 0.1 & 0.2 & 0.4 & 0 & 0 & 1 & Student 12 & 0.2 & 0.2 & 0.2 & 0.2 & 0.2 & 1 \\
\hline
\end{tabular}

The graphical representation (Figures 2 and 3) could be observed as showing better results of the control group in solving tasks concerning the limit of a sequence.

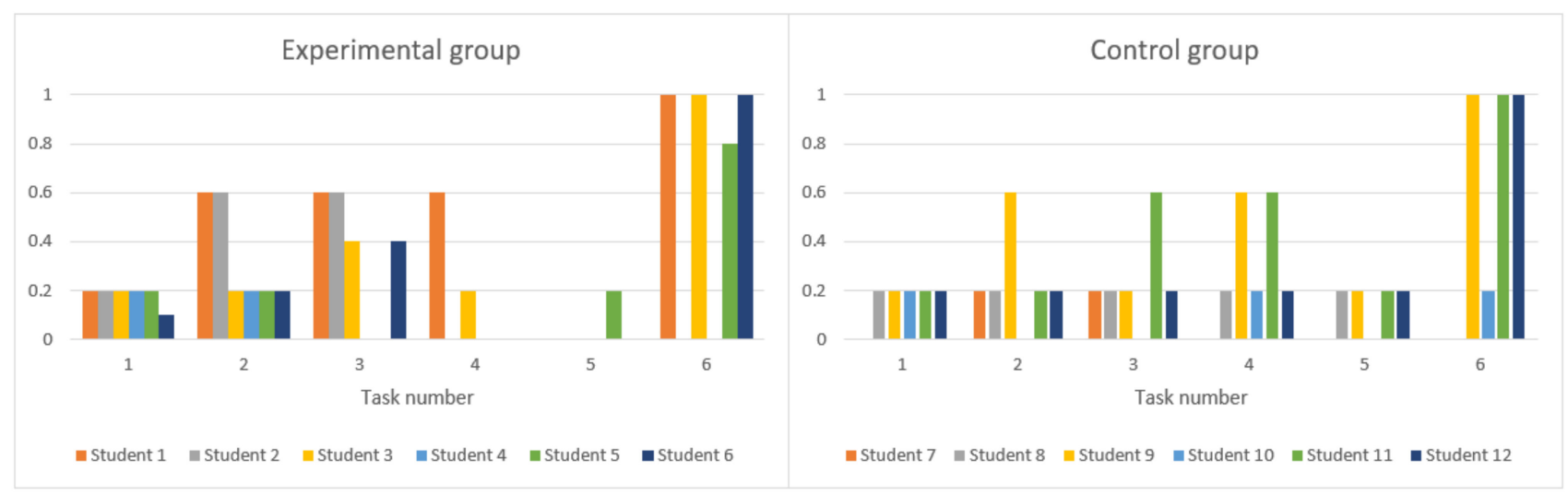

Figure 2. Graphical representation by tasks. 


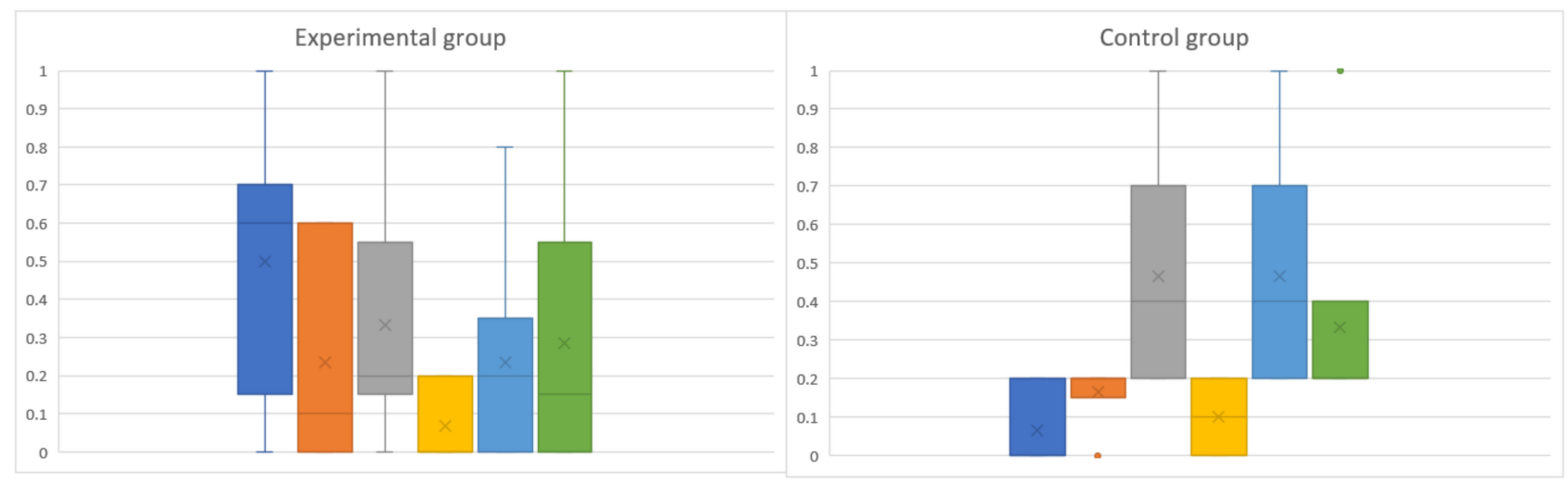

Figure 3. Results in groups for every PMT.

To get better insight into the results in the 1st test, we made a comparison of the average level of student's knowledge (Figure 4).

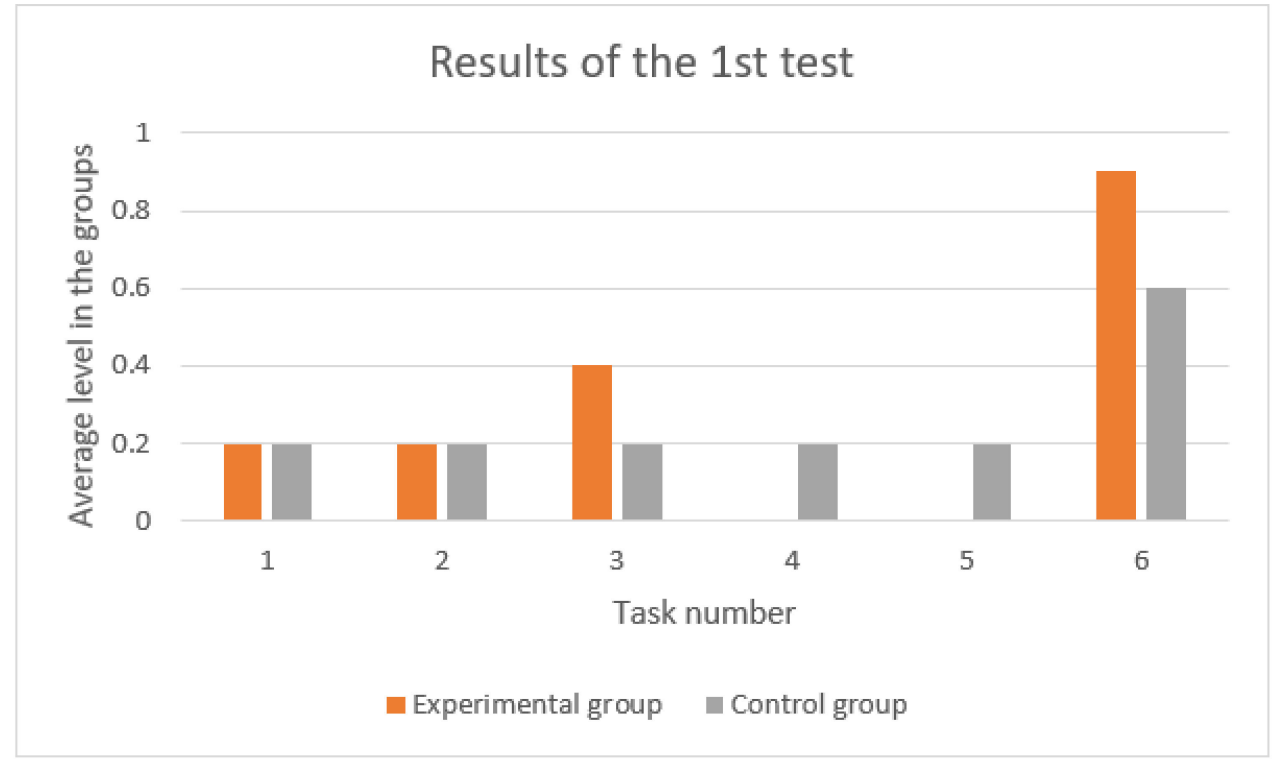

Figure 4. Median of the score in the groups by tasks.

Even though PMTs had a median score higher in tasks 3 and 6, we cannot conclude that their knowledge is higher. In the other tasks, the median of their score was zero.

There were three tasks on the limit of a function (1-3) and the rest on the derivative of the function (4-6) in the 2nd test. The making codes was the same as in the 1st test.

Table 9. Results of the 2nd test.

\begin{tabular}{|c|c|c|c|c|c|c|c|c|c|c|c|c|c|}
\hline Experimental Group & 1 & 2 & 3 & 4 & 5 & 6 & Control Group & 1 & 2 & 2 & 4 & 5 & 6 \\
\hline Student 1 & 0.2 & 0.2 & 0.8 & 0.4 & 0.4 & 1 & Student 7 & 0 & 0 & 0 & 0.4 & 0.8 & 0.8 \\
\hline Student 2 & 0.2 & 0.2 & 0.2 & 0.2 & 0.2 & 0.2 & Student 8 & 0 & 0 & 0 & 0 & 0 & 0 \\
\hline Student 3 & 0.4 & 0.6 & 0.6 & 0.4 & 0.4 & 0.8 & Student 9 & 0.4 & 0.6 & 0.6 & 0.4 & 0.8 & 1 \\
\hline Student 4 & 0 & 0.6 & 0 & 0.4 & 0.4 & 0.8 & Student 10 & 0 & 0 & 0 & 0.2 & 0.2 & 0.2 \\
\hline Student 5 & 0 & 0.6 & 0.6 & 0.4 & 0.8 & 1 & Student 11 & 0.2 & 0 & 0.2 & 0.4 & 0.8 & 1 \\
\hline Student 6 & 0.2 & 0.2 & 0.6 & 0.4 & 0.4 & 0.8 & Student 12 & 0.2 & 0 & 0 & 0.4 & 0.8 & 0.4 \\
\hline
\end{tabular}

To determine whether PMTs shift to a higher level of limit concept, we will focus only on the first three tasks in the test. Since we are interested only in the limit concept, the graphs are prepared for task 1 to 3 (Figures 5-7) 


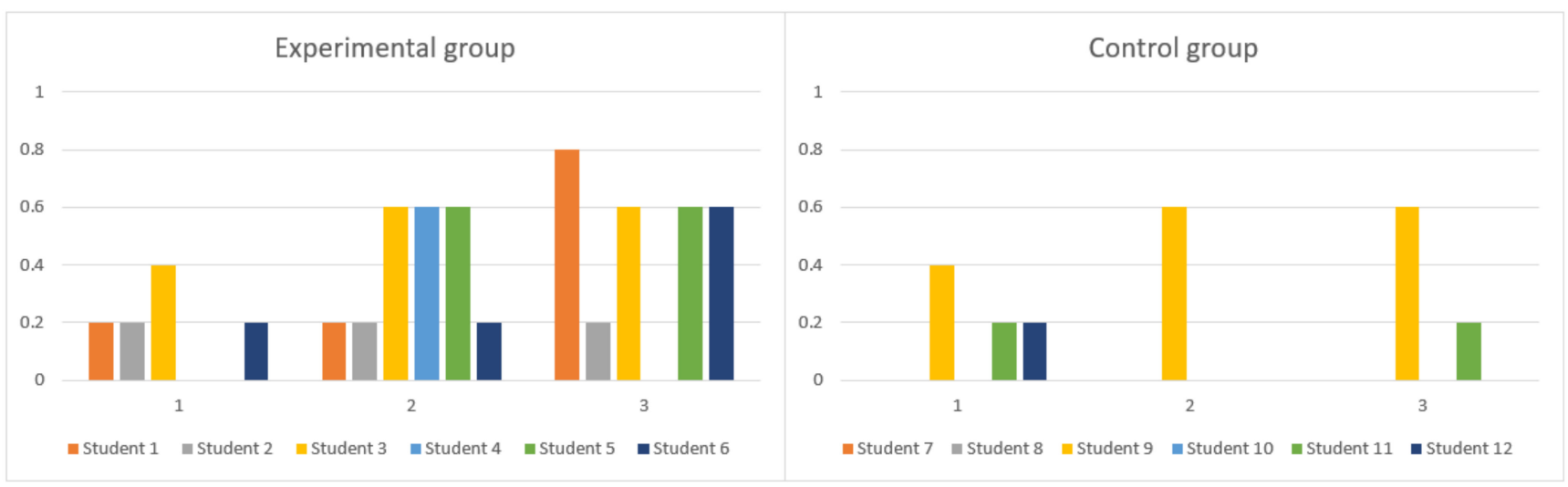

Figure 5. Score of the 2nd test by tasks.

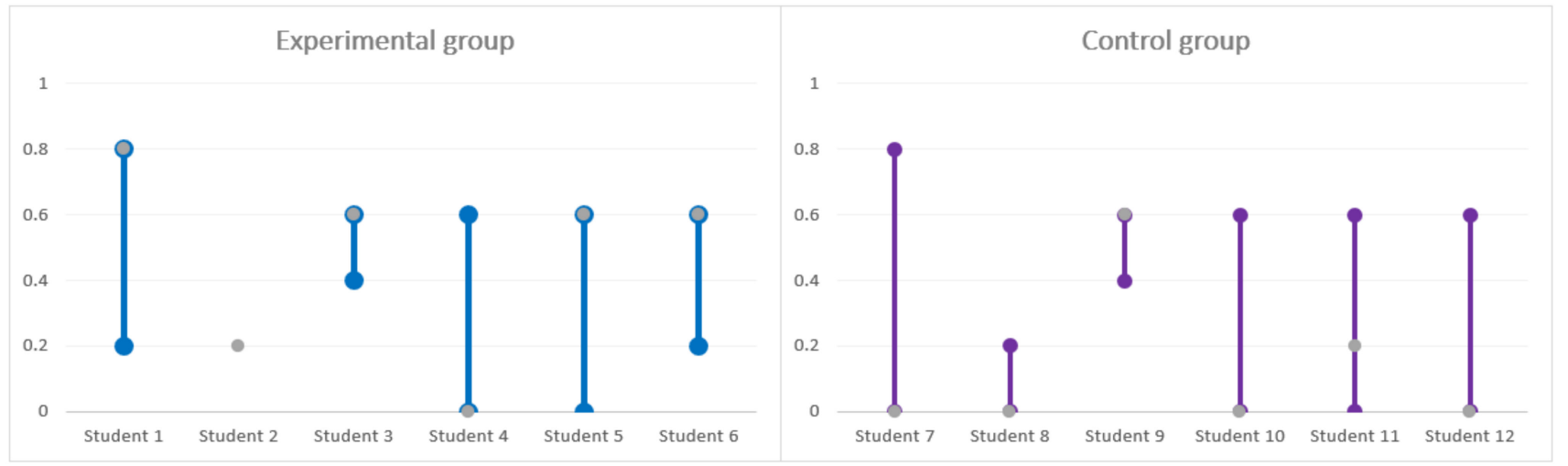

Figure 6. Score of the 2nd test by PMTs.

Looking at the graphs on the left side in Figures 5 and 6 (experimental group), one could observe that PMTs we more successful. Comparing the median of the scores of PMTs in both groups by tasks confirmed our assumption of a higher level of CK in the experimental group (Figure 7).

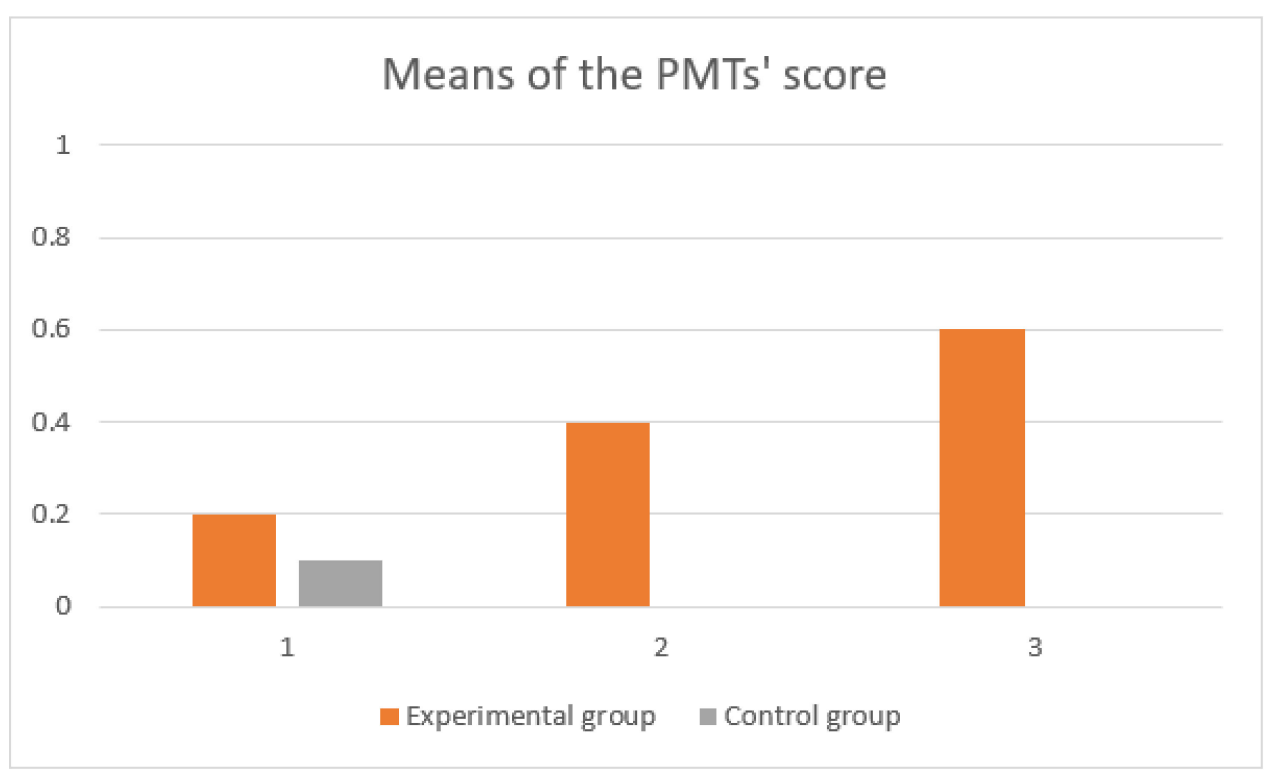

Figure 7. Mean of the score in the groups by the tasks. 
Due to the small groups of students, we were not able to reach or make any general conclusion. The progress which could be observed in the results was not significant. Therefore, we interviewed the PMTs. Since the groups were small, we did group interviews following the tests. Questions were asked about their strategies for solving, how they liked the tasks, whether they were challenging/easy to solve, etc. Two PMTs in the experimental group confessed that they had learned every task "word by word," so while they didn't understand what they were solving they were aware that "this is the way". The control group students thought the test was easy and they were delighted.

Even though we could not claim a general conclusion about the level of knowledge and whether the DT helped or not, we observed that students who worked with DT during the lessons were more active and more motivated. They tried to find out solutions without the help of the teacher. On the contrary, students in the control group were more dependent on the teacher's help.

The results in both groups were almost of the same level. We could only assume which group attained better and deeper knowledge from this part of the calculus. We could not say that the experimental group was better than the control group or vice versa. In both groups there were difficulties in solving and understanding the strategy of solving. Some PMTs tried to apply the memorized procedure without understanding it (for example, solving a limit of type " 1 to the infinity" as a limit of polynomials quotient). Another problem in both groups was working with infinity, like with a real number. As a mathematics teacher and educator with a lot of experience, we identified the following reasons for the aforementioned problems:

- The PMTs simply learn the way to solve without any understanding (they did it this way in secondary school and the habit remains).

- The PMTs do not know how to study alone or independently (they are not used to working alone, preparing systematically, studying ... ).

- When the PMTs were learning for the test, everything was clear, but they didn't try to find solutions alone. Without the help of the notebook or a teacher, they failed.

Some research results (e.g., [68,69]) pointed to students' difficulties with the concept of a limit due to an insufficient understanding of the basic concepts such as infinity (actual), sequence or function so we decided to implement DT into lectures as well. These studies mentioned that the factor influencing misunderstanding is the dialectics of quantifiers used in the limit's formal definition. So, changing the lectures from the scheme "definitiontheorem-proof" to more constructive could be especially helpful for the PMTs. Thus, the research in the 2nd phase was conducted in two lines-one line for changes in lectures, the second line for changes in exercises. Since we were looking at a different aspect of using DT, we changed the research question. We hypothesized that the influence of DT on PMTs knowledge could eventually be seen in time. Therefore, we focused on the construction of knowledge with DT support and its durability. The topic remains- the limit of a sequence and a function

\subsection{The 2nd Phase}

As we stated above, this phase of our research was focused on the durability of the mathematical knowledge obtained by the PMTs and DT's role in their mathematics' preparation. Therefore, the stated research question was: "Is knowledge (from mathematical analysis) developed through the use of digital technology more durable?" According to the results from [70] we assumed yes. We wanted to validate our assumptions about university level students with a higher level of mathematics.

There were two main differences compared with the 1st phase. First, we did not choose only one software for implementation in our lesson preparation. The reason was to offer our PMTs the possibility to look critically at several kinds of software and choose the one (or more) they felt more comfortable with or felt was better used in certain, specific situations. We offered them: Graphic Calculus, Derive, GeoGebra and we also provided the option of choosing any other mathematical software they were familiar with. We 
also hypothesized that if they saw the advantages of using DT in specific mathematical topics, they could better judge when to use DT as opposed to chalk and blackboard in their teaching practice. Second, this was the 1st year of teaching lectures as well for which we used a constructivist approach. Especially, we chose the social constructivism characterized in the Theoretical framework.

Since, in this research phase the author of this article taught using both, lectures and exercises, the research was conducted in two "parallel" lines:

- Lectures: focus on the process of conventionalization and transformation (according to [54]), these could be observable and encouraged by Socrative dialog.

- Exercises: how the chosen DT helped students to solve the problem tasks.

We started to work with a group of 18 PMTs, but at the end of our research, only 12 of them remained. Therefore, all evaluations are in respect to those 12 PMTs. We prepared a Moodle course to support the PMTs activity. In this course, extra tasks were uploaded to be solved by using DT. More than half of the students solved these tasks and uploaded their original solutions. They were encouraged to use DT with their preferred choice of software. We noticed that several students started to use their own computers with GeoGebra in lessons and to support mathematics' discussions. In the exercises, we noticed good preparation. The PMTs were aware and understood what we were talking about, what we were solving, why it worked that way, etc. We hypothesized that this phenomenon was observed possibly due to solving extra tasks in Moodle.

To measure the durability of students' knowledge in exercises, we wrote two tests with them. The first test was written at the end of semester, the second three months later (approximately in the middle of the following semester). Both tests focused on finding a limit of a function without the use of L'Hospital rule. To analyze the data that were obtained, we used the Wilcox test for small groups. It is a non-parametric statistical hypothesis test used when comparing two related samples, matched samples or repeated measurements on a single sample to assess whether their population mean ranks differ (i.e., it is a paired difference test). It can be used as an alternative to the paired Student's $t$-test, $t$-test for matched pairs or $t$-test for dependent samples when the population cannot be assumed to be normally distributed.

To answer the stated research question, besides the two tests with a 3-month gap and observations, we also compared the results with data obtained a few years ago from the groups taught traditionally (i.e., giving definition, theorem, lemma, proof, etc. with no DT support). Other supportive data for our claims were the state exams 2 years later. The PMTs from this research showed better insight into problematics when answering questions concerning the limit of function than the PMTs in the previous years. The PMTs involved in our research also provided correct solutions for the given tasks along with explanations. Therefore, we can conclude that DT and the constructivist teaching/learning environment support the durability of knowledge concerning the limit concept and finding limit of function without using L'Hospital's rule. The results are presented in the Table 10 and Figures 8 and 9.

Table 10. Results of the 1st and the 2nd test.

\begin{tabular}{ccccccccccccc}
\hline & $\mathbf{s 1}$ & $\mathbf{s 2}$ & $\mathbf{s 3}$ & $\mathbf{s 4}$ & $\mathbf{s 5}$ & $\mathbf{s 6}$ & $\mathbf{s 7}$ & $\mathbf{s 8}$ & $\mathbf{s 9}$ & $\mathbf{s 1 0}$ & $\mathbf{s 1 1}$ & $\mathbf{s 1 2}$ \\
\hline 1st test & 0.667 & 0.533 & 0.667 & 0.467 & 0.400 & 0.733 & 0.933 & 0.733 & 0.733 & 0.733 & 0.533 & 0.867 \\
2nd test & 0.656 & 0.563 & 0.688 & 0.594 & 0.750 & 0.781 & 0.750 & 0.750 & 0.625 & 0.625 & 0.781 & 0.875 \\
\hline
\end{tabular}

The average score of the 1 st test was $66.7 \%$, and for the 2 nd one $70.3 \%$ (see also Table 10 and Figure 8). 


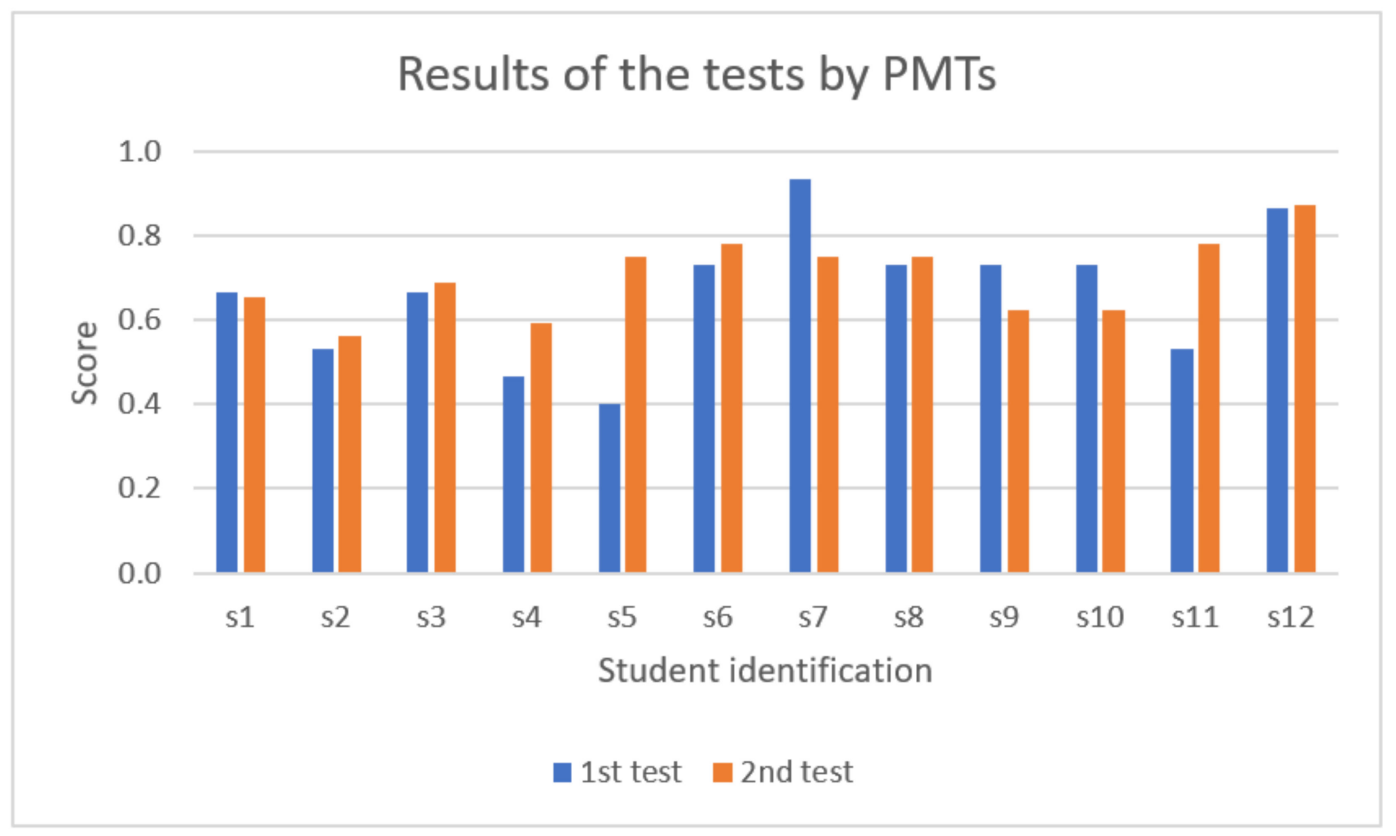

Figure 8. Result of the tests for each student.

To have better insight into the results, we used a quartile graph (Figure 9). The 2nd test results had a higher median and smaller range.

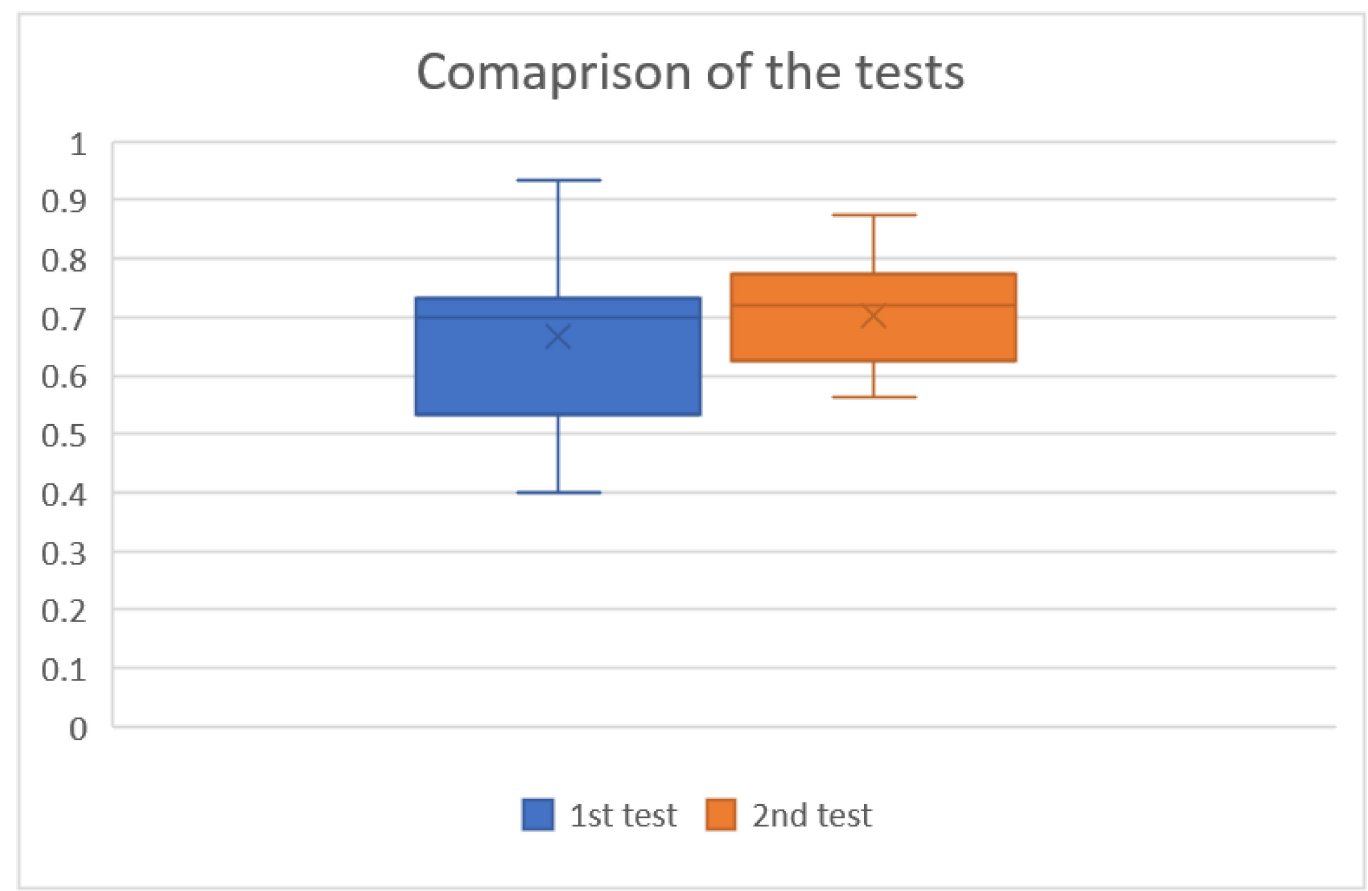

Figure 9. Quartile graph of the results of the tests.

We tested our hypotheses: "There is significant difference between the 1st and the 2nd test" to the null hypotheses: "There is no significant difference between the tests".

The criteria $W=\left|\sum_{i=1}^{n}\left(\operatorname{sgn}\left(x_{1 i}-x_{2 i}\right) R_{i}\right)\right|=18$ where $x_{1 i}$ are results of $i$-th student in the 1 st test, $x_{2 i}$-result of the $i$-th student in the 2 nd test, $R_{i}$ - the average rank of the ties. The critical values $W_{0.05}(12)=13$. Therefore, we do not reject the null hypotheses. Between the results there are no significant differences. 
We observed several shifts comparing the previous years in teaching PMTs. In the lectures, we observed a shift from the passive role at the beginning of the semester when students were listening and writing notes, to active participation of the PMTs having fruitful discussions at the end of the semester. By fruitful discussions we mean discussions about mathematical ideas, not mathematical notation. From this shift both PMTs and the teacher educator benefit. For PMTs, it is by formulating ideas, through construction of knowledge, the sharing/communication with their classmate(s). For the teacher educator, there is beneficial feedback about their teaching method. Concerning the model of sign appropriation and use, the process of conventionalization and transformation in the classroom was identified - a teacher-student communication pointed out an inner conflict between what was said and what they think it is like.

Our observations and the results of the tests tend to show that this approach could motivate the students to learn more, to be more active during the lessons and we can expect that they will be able to use DT in their own lessons when they will start teaching.

As we showed in our previous research [70], students' knowledge is more durable if this knowledge is a result of a construction rather than a passive reception. Therefore, we can assume that changes in the lessons based on DT can explain the good results of the students in testing. As Jonassen [71] proposes, the teachers and students should design DT based lessons and thus become knowledge constructors rather than knowledge users.

\section{Implementation DT into Applied Mathematics Subject-Development of TCK and TPACK}

In this part, we focus on implementing DT in the FM module of the PMTs preparation. The long-term research started in 2009 with a test of trial procedures for teaching FM to PMTs. We estimated intervention effects and piloted a small-scale intervention. There were three phases of research.

\subsection{Phase 1: Explanatory Study of PMTs Financial Literacy}

The aim was to determine the financial literacy of secondary school graduates (in our case, students in their 1st year of study in our teacher training programme). Our sample of the students did not follow the course of FM at secondary schools. We conducted our research following the analysis of students' solutions following the Theory of didactical situations [53]. The first important issue was identifying the target knowledge (it is not always explicit and not always the one expressed by the teacher) and how it appeared in the problem to solve. The second one was to identify the milieu (similarly to $[47,48]$ ): data and all actual givens usable by students without any teacher intervention. The third one was to identify students' prior knowledge, foresee actions students may undertake in this milieu, and how they could interpret feedback arising from it. In achieving this, we elaborated an a priori analysis of the class situation. The milieu of the material should activate the student to the activity, which could lead to obtaining the targeted knowledge.

We prepared a test comprised of 4 tasks from real life, which every secondary school graduate should be able to solve without any problems. Then we made a priori analysis. We identified possible solving strategies, possible obstacles, the structure of the milieu (we started with an Objective situation and finished in a Didactical situation. The PMTs did not reach the situation of learning, but that was not the aim of our effort).

For descriptions of the milieu's vertical structure in the a-didactic situation, we used the scheme according to Perrin-Glorian [72] due to the classification which corresponds with our prepared situations in the Financial Mathematics courses (Figure 10). 


\begin{tabular}{llll}
\hline $\begin{array}{l}\mathrm{M}_{1} \\
\text { didactic milieu }\end{array}$ & $\begin{array}{l}\mathrm{E}_{1} \\
\text { universal subject }\end{array}$ & $\begin{array}{l}\mathrm{P}_{1} \\
\text { teacher } \\
\text { the class }\end{array}$ & $\begin{array}{l}\mathrm{S}_{1} \\
\text { Metadidactic } \\
\text { Situation }\end{array}$ \\
\hline $\begin{array}{l}\mathrm{M}_{0} \\
\text { learning milieu }\end{array}$ & $\begin{array}{l}\mathrm{E}_{0} \\
\text { Student }\end{array}$ & $\begin{array}{l}\mathrm{P}_{0} \\
\text { Teacher }\end{array}$ & $\begin{array}{l}\mathrm{S}_{0} \\
\text { Didactic Situation }\end{array}$ \\
\hline $\mathrm{M}_{-1}$ & $\mathrm{E}_{-1}$ & $\mathrm{~S}_{-1}$ \\
reference milieu & epistemic subject & & Learning Situation \\
\hline $\mathrm{M}_{-2}$ & $\mathrm{E}_{-2}$ & $\mathrm{~S}_{-2}$ \\
objective milieu & acting subject & & Reference Situation \\
\hline $\mathrm{M}_{-3}$ & $\mathrm{E}_{-3}$ & $\mathrm{~S}_{-3}$ \\
material milieu & objective actors & & Objective Situation \\
\hline
\end{tabular}

Figure 10. Vertical structure of the milieu in a-didactic situation (source [72]).

The crucial part of the a priori analysis was identifying possible correct and incorrect strategies of solving. We made graphs as in Figure 11 of hypothetical strategies of solving for each task. In this place, we demonstrate possible incorrect strategies for solving the following task:

We would like to set up new bank account and deposit $100 €$ every month starting at the beginning of the year. The deposit will always be made at the beginning of the month. We know that "our bank" offers a $2.3 \%$ fixed interest rate (the interest rate will not change through the year). The interest rate is calculated and deposited only once to our account, and always at the end of the calendar year. How many $€$ would we have in the account by December 31 st with a $2.3 \%$ interest rate? How many $€$ would we save by the end of the year if we would put $100 €$ every month to our piggy bank? [37] (p. 128).

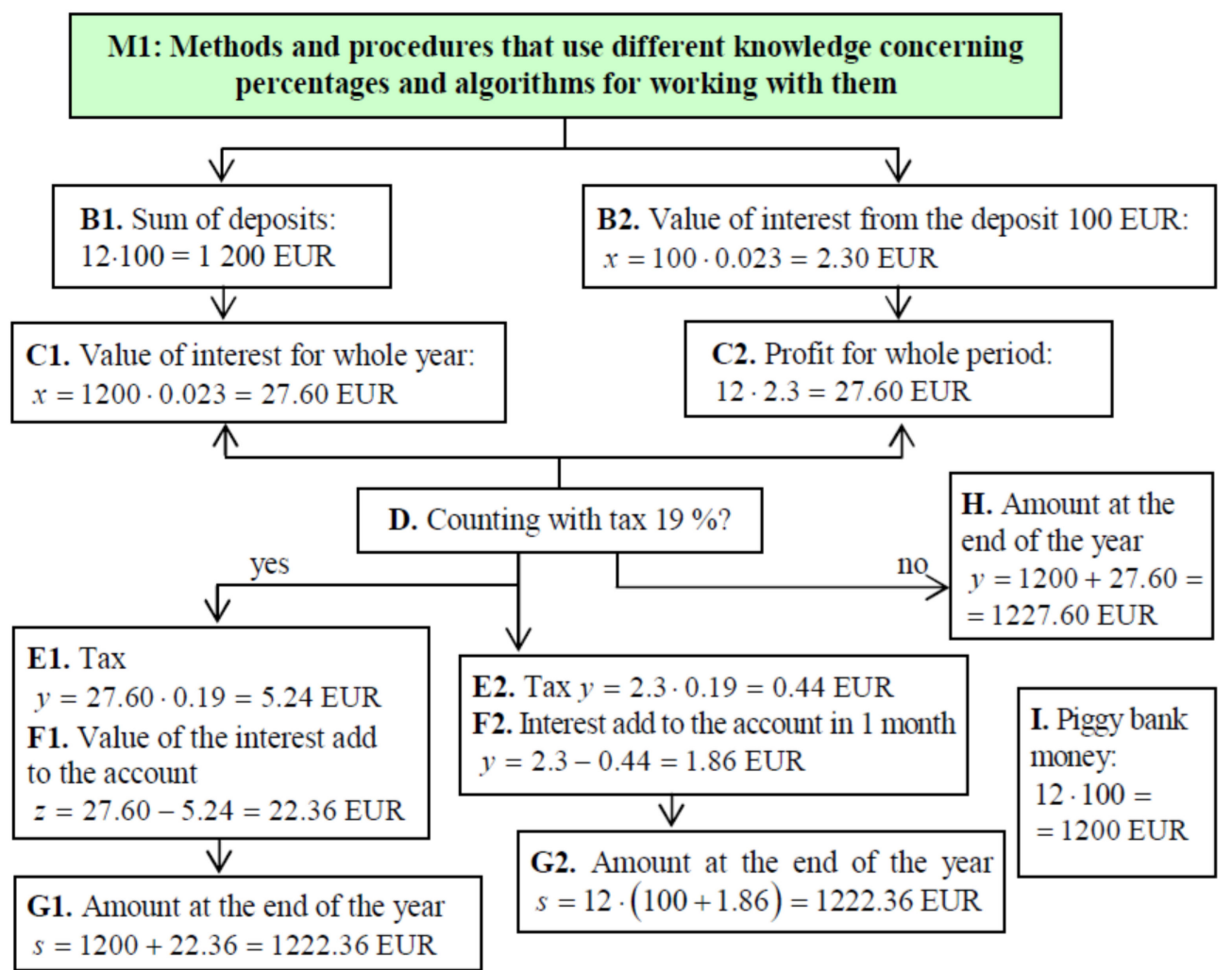

Figure 11. A priori analysis-possible incorrect strategy of solving of chosen task (source: [37], p. 128). 
We tested all 25 PMTs in the 1st year of study at our institution in 2008/2009. They could use only a pen, paper and calculator. After the test, we compared our projection from a priori analysis of students' solutions and evaluated a posteriori analysis. We used a similar scheme as in Figure 11 to analyze PMTs solutions (for detailed information, see [37]).

In the a posteriori analysis we identified the Objective situation $\mathrm{S}_{-3}$ (Figure 10) the same in every strategy. PMTs acquaint with the tasks and Material milieu $\mathrm{M}_{-3}$. The material part of $\mathrm{M}_{-3}$ included basic writing tools (paper, pen ... ), the mathematical and real context of the task. The Cognitive part of $\mathrm{M}_{-3}$ contains knowledge and understanding of different levels. The level depends on the secondary school from where the students graduated, their age, and the strategy used. This is mostly knowledge concerning interest, interest rate, payment amount, mortgage and the necessary mathematical tools for solving the given tasks. The Social part of the $\mathrm{M}_{-3}$ was minimized because it was not desirable to have any distractions while solving the tasks.

In the Reference situation, $\mathrm{S}_{-2}$, the PMTs tried to solve the tasks in an already familiar milieu $\mathrm{M}_{-3}$. PMTs used only known schemas, relations, procedures, algorithms. In situation $\mathrm{S}_{-1}$, a Learning situation, the PMTs were in the position being the problem solvers. The nature of the activity involved loss so the PMTs had to think more and start to formulate answers to the questions which they asked themselves. The realization of the basic research did not assume any interruption to the PMTs solution. PMTs did not reach Didactical situation $\mathrm{S}_{0}$.

In general, from the solution to the whole test, we observed that PMTs in the 1st year of their study are not familiar with the basic terms of FM, their understanding having come from the advertisements promoting mortgages, credits, loans, leasing and other financial products sold by banks and other financial institutions. This limitation influenced the choice from the concrete offer of financial institutions. This choice was often without any logical correct counting or guesses. Therefore, students not only failed in this field of mathematics and but in a real-life situation.

According to the result of the 1st phase of our research, we prepared study material with 42 tasks and suggested intervention by using DT, which is described in phase 2 of the research.

\subsection{Phase 2: Intervention}

The aim was to find out if the study material prepared for teaching FM with the implementation of DT improves (a) knowledge of the PMTs in the 1st year of study at our faculty; (b) the PMTs ability to prepare their own teaching sequence of FM. This curricular change should permit the PMTs to obtain the necessary knowledge of FM needed for both for usage in real life and notably in their future career as teachers of mathematics at secondary school.

We prepared 42 tasks and divided them into 2 thematically independent parts. The 1st part focused on bank accounts, fixed deposits, bank books and different types of savings products. The 2nd part focused on different types of loans, leasing and credit. We tested a sample of 25 PMTs in the 1st year of study (2 groups of students). The PMTs in both groups did a pre-test in the same week. Students in the groups were taught by different teachers (both teachers were authors of paper [38]). The PMTs were unaware that they would be involved in an experiment. The teaching/learning process started one week after the pretest. The innovation of teaching was not only in adding a new topic into the existing subject. The approach to the problem was different. We started to use DT as a demonstration tool, but students also had computers to make their own simulations, calculations and modelling. The PMTs had the possibility to use DT to do their homework, etc. Using the DT was common, the individual work of the students was necessary and the PMTs could prepare homework by using DT. Approximately two weeks after the intervention, a posttest was written. The post-test tasks were equivalent to the pre-test tasks (the mechanisms remained the same, the context of the tasks and numerical values differed). 
According to the teaching/learning process, we specified one task for every student to solve. They had one week for preparation. Therefore, the PMTs realized the situation of action in a home environment. The situation of formulation was realized in the school environment or dormitory, depending on the PMTs' preferences. There was an opportunity to discuss the PMTs hypotheses amongst their peers during the whole week. Validation of the PMTs hypotheses started during the presentation of their solutions in the lesson. There was discussion among the PMTs themselves and between the PMTs and teachers. The institutionalization of any new knowledge was up to the teacher.

During the teaching, we were also observing the students' behaviour, their attitude towards the organization of work in the lessons. It, of course, varied from student to student. Most girls were discouraged because of computers. In the Table 11 most common solution by PMTs is shown (in both pre-test and post-test).

Table 11. Most common solution of chosen task from pre-test and post-test.

\begin{tabular}{cl}
\hline & Pre-Test \\
\hline Sum of deposits: & $12 \times 100=1200$ \\
Conunting with tax 19\% & $2.3 \% \times 0.19=0.44 \%$ \\
Interest rate after taxation & $2.3 \%-0.44 \%=1.86 \%$ \\
Value of the interest add to the account & $1200 \times 0.0186=22.356 \mathrm{EUR}$ \\
At the end of year & $1200+22.356=22.356 \mathrm{EUR}$ \\
Piggy bank money & $12 \times 100=1200 \mathrm{EUR}$ \\
\hline & Post-Test \\
\hline Sum of deposit and interest (in EUR) in three months separately, so in the one quarter: \\
January: & $100+100 \times \frac{1}{12} \times \frac{2.3}{100} \times 0.81=100.155$ \\
February: & $100+100 \times \frac{2}{12} \times \frac{2.3}{100} \times 0.81=100.311$ \\
March: & $100+100 \times \frac{3}{12} \times \frac{2.3}{100} \times 0.81=100.446$ \\
July: & $100+100 \times \frac{6}{12} \times \frac{2.3}{100} \times 0.81=100.932$ \\
Total sum: & $100+100 \times 0.81\left(\frac{1}{12}+\frac{2}{12}+\ldots+\frac{12}{12}\right)=1212.11$ \\
Piggy bank money: & $12 \times 100=1200 \mathrm{EUR}$ \\
\hline
\end{tabular}

To analyse the data, we used the same graphical representation of the possible paths to a solution as in phase 1. From the pre-test and post-test results of each PMT, we could see that they tried to use learned procedures and apply presented mechanisms to solve the tasks after attending the FM module. However, it was not always correct. One of the possible reasons could be the didactical contract [40], the students' effort to apply obtained knowledge in any way. However, the higher level of task 1 in the post-test compared to the pre-test could be why only 4 students got the correct answer to the question. In general, we can say that following the FM module students can apply the methods and tools of FM but with some issues. Their knowledge of FM was not institutionalized during the FM course.

This phase of our study focused on developing CK and TCK, but there should be a balance between developing future teachers' CK and their PCK. The question was, what approaches on the part of teacher educators can help future teachers to develop all aspects of their knowledge for teaching (knowledge of math, ways of teaching math and ways in which students learn math) at the same time.

\subsection{Phase 3: Financial Literacy of PMTs and Real-Life Experiences}

Even though this phase is not directly connected to the implementation of DT into PMTs preparation, it has a crucial role in the identification of how real-life experiences could affect our view of the world. In the specific cases, it could show PMTs that reallife experiences are an integral part of their future pupils' knowledge, affecting pupils' perception of mathematics concepts. This has a strong connection to PCK and TPACK in PMTs preparation.

The aim was to determine how the PMTs' awareness, understanding and experience about FM outside school learning situations influenced their participation in school activ- 
ities as they became acquainted with formal mathematical principles and conventional mathematical notations. After four lessons in FM focused on understanding the basic financial mechanisms, the PMTs were tested. The test's main purpose was to determine the level of understanding of the financial terms and mechanisms. The results of the test showed that the PMTs' knowledge was insufficient. In fact, their knowledge of financial mathematics appeared to be extremely poor. (see phases 1 and 2)

As a result, we changed the intervention, taking new approaches to demonstrate the mechanism. We selected one task for each mechanism and analysed it in detail from two points of view: mathematical (how to solve it and why it works) and didactical (the most common misconceptions of students and when to use specific kinds of example, etc.) We selected the test tasks similarly as in phase 1 and phase 2 (to cover the most used mechanisms of FM everyone should be familiar with).

The PMTs' perplexed and negative reactions to the teaching of FM led us to consider the PMTs existing experiences in our experiment. To understand the PMTs' awareness of and experiences with financial products and impact PMTs' experiences on their solutions of school tasks, we used questionnaire survey. PMTs were asked about their income, bank and savings accounts, loans, their source of financial information (such as television, internet, press, school, family environment and community of friends). We did not ask PMTs for personal information like the precise amount of money they have. The questions were very general, like Do you have a regular income? If yes, select all possibilities: pocket money, part-time job, full-time job, etc.

We required them to self-reflect on their FM knowledge. We assumed that students with personal experiences with financial products would have better results in the school test from FM (tasks focused on saving accounts and loan products). Therefore, we chose these two methods of collecting data to find out the answer to our research question: What is the influence of experience on PMTs financial literacy?

Our classroom research involved 16 PMTs (aged 22-28) attending the last two years of university-level studies. We therefore assumed that they would be able to connect their "everyday" thinking properly with "school" mathematical models.

We examined how mathematical ideas from FM are represented differently in the school and outside the school. Most of the PMTs had big difficulties understanding the terms and terminology used in the tasks (e.g., "annuity-it is probably the interest", "principal is probably something totally unimportant and pointless which can be calculated from the first two cells", etc.). We also found out that the PMTs who had opened a savings account did not necessarily understand how it really worked. $31.25 \%$ of the students had applied for a bank loan (or students' fund loan) in the past but they had no idea why they paid the amounts they paid and how the bank calculated the annuity. Furthermore, their understanding of how money is valorised is largely unreal.

As can be observed in Table 12, the easiest task for students was an application of income tax knowledge $\left\{\mathrm{u} 1 \_d a n\right\}$ and the mechanism of a short-term loan $\left\{\mathrm{u} 2 \_\right.$roc $\}$. Students obtained good results also in the task \{u2_urok\} which required an understanding of the difference between interest rate and interest. Our findings indicate that students are not familiar with the monthly interest mechanism \{u1_mes\} and with the annuity term $\{\mathrm{u} 3\}$. In addition, approximately $50 \%$ of students were able to apply their knowledge of annual payment \{u4_splatka\} and of debt payment \{u4_dlh\}. The problem in this task concerned the meaning of principal \{u4_istina\}. 
Table 12. Means and standard deviations for financial knowledge of solved tasks.

\begin{tabular}{|c|c|c|c|c|c|c|c|c|c|c|}
\hline \multicolumn{2}{|c|}{ u1_dan } & \multirow{2}{*}{-} & \multicolumn{2}{|c|}{ u1_mes } & \multirow{2}{*}{ - } & \multicolumn{2}{|c|}{ u2_roc } & \multirow[t]{2}{*}{-} & \multicolumn{2}{|c|}{ u2_urok } \\
\hline Average & SD & & Average & SD & & Average & SD & & Average & SD \\
\hline 0.81 & 0.4 & - & 0.06 & 0.25 & - & 0.82 & 0.4 & - & 0.75 & 0.44 \\
\hline \multicolumn{2}{|c|}{$\mathbf{u} 3$} & - & \multicolumn{2}{|c|}{ u4_splatka } & - & \multicolumn{2}{|c|}{ u4_dlh } & - & \multicolumn{2}{|c|}{ u4_istina } \\
\hline Average & SD & - & Average & SD & - & Average & SD & - & Average & SD \\
\hline 0.06 & 0.25 & - & 0.44 & 0.51 & - & 0.5 & 0.52 & - & 0.13 & 0.34 \\
\hline
\end{tabular}

For the analysis of the collected data (both test and questionnaire), the hierarchical clustering of variables and Gras' implicative statistical method was also conducted by using a computer software called C.H.I.C. (Classification Hiérarchique, Implicative et Cohésitive) [73]. We used this software because it fulfilled our requirements for the data analysis we required. These methods of analysis determine the similarity of hierarchical connections and the implicative relations of the variables, respectively [74]. For the needs of this study, four similarity diagrams (like in Figure 12) of the PMTs responses to the tasks of the test and questionnaire were produced. The similarity diagrams allow for the arrangement of the tasks into clusters according to the homogeneity by which they were handled by the students.

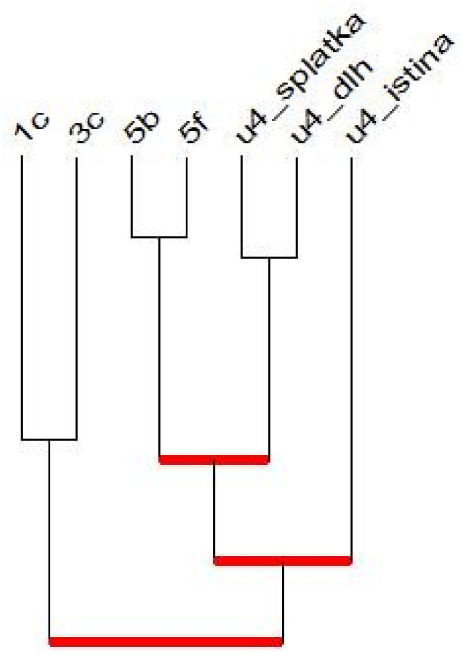

Figure 12. Similarity tree, example of evaluation of data (source: [75]).

Figure 12 presents the similarity diagram of the students' responses to the tasks $u 4$ (concerning long-term loans) influenced by their everyday experiences (answers from questionnaire's items). In the diagram two significantly related clusters are identified. The first cluster describes students' working experiences $\{1 c\}$ and $\{3 c\}$. The second cluster is comprised of two significantly related subgroups. The first subgroup describes the relation between students' experiences with loans $(\{5 b\},\{5 f\})$ and knowledge about what annual payment consists of $\left\{\mathrm{u} 4 \_\right.$splatka\} and how to pay off debt $\left\{\mathrm{u} 4 \_\mathrm{dlh}\right\}$ ). This subgroup has significant similarity to knowledge concerning the meaning of principal \{u4_istina\}.

Comparisons of the students' test results and answers to the questionnaire show that they are strongly influenced by the family and media (TV, internet, social media, etc.). $25 \%$ of the PMTs thought that information from school is partially or mostly sufficient and 50\% of them thought the same about information from the media.

Our analysis implies that everyday experience has a direct impact on the students' ability to solve FMs' tasks. Therefore, we can consider our assumption of the research that "students with personal experience with financial products are likely to have better results in the school test from FM" to be correct. 
This phase of the research helped us to better understand the relationship between students' everyday experiences and their skills concerning FM in the lessons. On one hand, this finding should help us improve the preparation of the courses for PMTs, to change the approach to the students regarding their experiences with "everyday" knowledge and also help us prepare a guideline for how to start with FM at the secondary school level. On the other hand, results showed our PMTs how everyday experiences influence their perception of mathematics. Therefore, they should think about it when teaching in their future career as mathematics teachers.

\section{Discussion}

We presented two streams of our research concerning the implementation of DT into PMTs preparation, implementation of DT into the theoretical subject (Calculus) and implementation into an applied mathematics' subject (Financial Mathematics).

Concerning Calculus: The format of the lectures and exercises remained the same as described in the 2 nd phase of the research (see Section 4.2) in the following years (we have been collecting data since the year 2012). We needed to be more focused on several types of tasks solved in the lessons. Therefore, we used Revised Blooms Taxonomy [76] to identify the cognitive and knowledge dimension we should focus on for the tasks solved in the lessons (yellow shaded region) and in the tests (red shaded region) as shown in Figure 13.

\begin{tabular}{|l|c|c|c|c|c|c|}
\hline & Remember & Understand & Apply & Analyze & Evaluate & Create \\
\hline Factual & $\mathrm{x}$ & $\mathrm{x}$ & $\mathrm{x}$ & $\mathrm{x}$ & & \\
\hline Conceptual & $\mathrm{x}$ & $\mathrm{x}$ & $\mathrm{x}$ & $\mathrm{x}$ & $\mathrm{x}$ & \\
\hline Procedural & $\mathrm{x}$ & $\mathrm{x}$ & $\mathrm{x}$ & $\mathrm{x}$ & $\mathrm{x}$ & \\
\hline Metacognitive & & & & & & \\
\hline
\end{tabular}

Figure 13. Cognitive and Knowledge dimension (source: [64]).

We also looked at the PMTs' misconceptions which played a role in creating barriers that prevented understanding of the Calculus concepts [77], geometrical perspective as the introduction in the limit process [65] and the PMTs' misconception in understanding the definition of a limit of a sequence [66].

Concerning Financial Mathematics: When the new teacher preparation study program started in 2014, we shifted Financial Mathematics to the subject "Didactics of Mathematics" and "Methods of solving mathematical tasks". The PMTs also started to develop TPACK alongside TCK. The PMTs' work as described above (preparation of lessons with the integration of DT in solving Financial Mathematics' tasks) include a project as well as experiences. The use of DT in these lessons was more natural for two reasons (from our point of view). Firstly, students were more experienced (they were studying for a Master's degree, not a Bachelor's). Secondly, they appreciated the power of using specific software for presentation, collaboration and explanation (based on discussions in the lessons).

In general, we observed several differences when implementing DT into these two kinds of subjects. First, the PMTs were more willing to use DT in Financial Mathematics than in Calculus lessons. There could be several reasons for this. Financial mathematics was taught as a part of a didactical subject, so there was a clear connection to school Mathematics and the PMTs usually felt comfortable and familiar with the topic. On the other hand, Calculus was, for most of them, too theoretical, "far" from the school Mathematics and difficult to understand (based on the results of an internal evaluation of the educational process by students, held every examination period of the year). Another problem could be in the curriculum. Before the year 2014, students had 5 semesters of getting to know different DT resources. After the year 2014, new subjects concerning using DT were added to the PMTs curriculum. This programme will not continue beyond the writing of this paper. A new study programme will be prepared for 2021-2022 reflecting the findings from our research. Changes in PMTs attitudes after implementing DT into 
their curricula was also observed by Ndlovu et al. [78]. They recommended that educators should integrate DT as early as possible in initial teacher education curricula. Kendal and Stacey [79] pointed, "the teacher who stressed understanding moved away from using CAS, whilst the teacher who stressed rules, adopted it more" (ibid, p. 143). Therefore, both teacher educators' beliefs and how the DT is used are crucial and influence the results.

Second, in both streams, we identified a group of PMTs who were "afraid" of computers. Even when year by year the level of DT skills of PMTs increases, the willingness to use DT stagnates (we assumed the direct proportion here). Students with lower DT skills responded when questioned that they are "tired of using DT" because they are "forced to use it almost everywhere". Students with at least average DT skills were more willing to use DT in lessons or for home preparation. This research topic changed in 2020 due to the world-wide pandemic caused by the COVID-19 virus. Distance learning forced all PMTs (and all other students in Slovakia) to work with DT every day. They had to learn how to use new kinds of software, become familiar with new communication environments, discover and learn how to share their ideas in a digital world with less effort and time, etc. The subgroup of PMTs with low (or lower) DT skills struggled with this shift into the digital world. Drijvers et al. [80] identified six orchestration types from which Discuss-the-screen and Explain-the-screen were technological variants of regular teaching practices most teachers are familiar with. We used these approaches too in both streams of our research.

Third, in both cases, there was a strong correlation between the PMTs' level of DT skill and their activity in the lessons, particularly in part focused on modelling mathematical situations. The PMTs with lower DT skills were more observant and then began to be more active in exercises. Their questions were more connected to procedural skills than the understanding of concepts and why procedures work. Looking at the PMTs activity, other phenomena arise. Many PMTs had significant misconceptions of a function concept. That could be one reason for the mistakes they made when modelling situations concerning the limit process. There were 2 PMTs in 2012 who believed the software so much that they considered the graph of $y=2^{|x|}$ as being same as $y=2|x|$. In the beginning, we assumed that it was only a notation problem in DT. However, when we asked them how we can be sure that the shown graph is a graph of the function we are talking about, they answered that it was true because the software drew it that way. What was alarming was that the number of students with little knowledge of functions was increasing year by year. In 2019 more than half of the PMTs had no idea about elementary functions and their properties. They relied on the result provided by the chosen software. Ferrara et al. [81] declared, "the use of CAS appears helpful to clarify problem solving strategies, but the adoption of higher order mathematical conceptions behind procedures seems to be limited" (p. 245).

Fourth, in both cases, there was no significant difference in procedural skills. Chappel and Kilpatrick [20] declared the same result on the sample of more than 300 students of calculus. However, similarly, "students enrolled in the concept-based learning environment scored significantly higher than the students enrolled in the procedure-based learning environment" (ibid, p. 17). This phenomenon was observed on FM lessons too. Petrášková and Hašek [82] implemented smart documents and interactive sheets in PMTs preparation had the same result in FM. However, they stated that PMTs who used DT in the lessons had twice higher ability to apply the knowledge of FM in practical tasks. Implementation of DT also increases TCK. The access to "all I need" to solve the task encourage PMTs to work.

Fifth, we observed a marginal benefit in both streams of our research. Introvert PMTs were more engaged with using DT. A similar result is presented in [83].

\section{Conclusions}

In this paper we presented two threads (or streams) of research made of groups of PMTs since 2008. We do not say that these have been the only research done in this time period. We wanted to point out differences in the implementation of DT into the PMTs' preparation of different types of lessons (theoretical and applied) and their influence on PMTs CK, TCK or TPACK. How the PMTs' behaviour changed, how it helped to improve 
some of their skills (e.g., understanding of concept) but others remains at the same level (e.g., calculations).

New questions were raised by our which remain open:

- How to find out if the DT helps the students to understand? Some connected questions to the stated one: How to measure PMTs understanding? What was the role of teacher personality?

- How to find out if the DT helps the students to obtain more durable knowledge?

- Are the results of the test influenced by DT or by the change of the teacher's approach?

More large-scale research in this area is needed, both in theoretical and applied subjects in the preparation of PMTs.

Funding: This research received no external funding.

Institutional Review Board Statement: Not applicable.

Informed Consent Statement: Not applicable.

Data Availability Statement: Not applicable.

Acknowledgments: This article is related to the goals that we hope to accomplish in the H2020 project MaTeK, no. 951822 and in collaboration with Jarmila Novotná from the Faculty of Education of Charles University.

Conflicts of Interest: The author declare no conflict of interest.

\section{References}

1. Sacristán, A.I.; Calder, N.; Rojano, T.; Santos-Trigo, M.; Friedlander, A.; Meissner, H.; Tabach, M.; Moreno, L.; Perrusquía, E. The Influence and Shaping of Digital Technologies on the Learning-And Learning Trajectories-Of Mathematical Concepts. In Mathematics Education and Technology-Rethinking the Terrain; Hoyles, C., Lagrange, J.B., Eds.; New ICMI Study Series; Springer: Boston, MA, USA, 2009; Volume 13, pp. 179-226.

2. Šedivý, O.; Vallo, D.; Vidermanová, K. Nové Trendy v Teórii Vyučovania Matematiky. Dynamický Softvér Vo Vyučovani; UKF: Nitra, Slovakia, 2011.

3. Dockendorf, M.; Solar, H. ICT integration in mathematics initial teacher training and its impact on visualization: The case of GeoGebra. Int. J. Math. Educ. Sci. Technol. 2017, 49, 1-19. [CrossRef]

4. Jančařík, A.; Novotná, J. The role of computers in pre-service teacher training-Are our graduates ready for the challenge? In Proceedings of the Aplimat 2013: 12th Conference on Applied Mathematics, Bratislava, Slovakia, 5-7 February 2013; pp. 351-358.

5. Arbaugh, F.; Herbel-Eisenmann, B.; Ramirey, N.; Kranendonk, H.; Knuth, E.; Quanedr, J.R. Linking Research and Practice: Practitioner Community Priorities for Research in Mathematics Education; The NCTM Research Agenda Conference Report; NCTM: Reston, VA, USA, 2010.

6. Ernst, K.; Ryan, S. Success from the Start: Your First Years Teaching Elementary Mathematics; NCTM: Reston, VA, USA, 2014.

7. Cohen, J.; Hollebrands, K.F. Technology tools to support mathematics teaching. In Focus in High School Mathematics: Technology to Support Reasoning and Sense Making; Dicks, T.P., Hollebrands, K.F., Eds.; NCTM: Reston, VA, USA, 2011; pp. 105-122.

8. Jančařík, A.; Novotná, J. Potential of CAS for development of mathematical thinking. In Aplimat 2011: 10th Conference on Applied Mathematics; Kováčová, M., Ed.; STU: Bratislava, Slovakia, 2011; pp. 1375-1384.

9. Hoyles, C.; Lagrange, J.B. Introduction to mathematics education and technology-rethinking the terrain: The 17th ICMI Study. In Mathematics Education and Technology—Rethinking the Terrain: The 17th ICMI Study; Hoyles, C., Lagrange, J.B., Eds.; Springer: New York, NY, USA, 2009; Volume 13, pp. 1-15.

10. Gruson, B.; Gueudet, G.; Le Hénaff, C.; Lebaud, M.-P. Investigating Teachers' Work with Digital Resources. A Comparison Between the Teaching of Mathematics and English. Schweiz. Z. Bild. 2018, 40, 485-501. [CrossRef]

11. Abdelhafez, A. Digitizing Teacher Education and Professional Development during the COVID-19 Pandemic. Acad. Lett. 2021. Article 295. [CrossRef]

12. Williams, S.R. Models of limit held by college calculus students. JRME 2011, 7, 87-104. [CrossRef]

13. Guin, D.; Trouche, L. Seeing is Reality: How Graphic Calculators May Influence the Conceptualization of Limits. In Proceedings of the PME 20: 20th Conference of the International Group for the Psychology of Mathematics Education, Valencia, Spain, 8-12 July 1996; Puig, L., Gutiérrez, A., Eds.; Universitat de València: Valencia, Spain, 1996; Volume 4, pp. 323-330.

14. Cottrill, J.; Dubinsky, E.; Nichols, D.; Schwingendorf, K.; Thomas, K.; Vidakovic, D. Understanding the limit concept: Beginning with a coordinated process scheme. J. Math. Behav. 1996, 3, 167-192. [CrossRef]

15. Tall, D.; Thomas, M.; Davis, G.; Gray, E.; Simpson, A. What is the object of the encapsulation of a process? J. Math. Behav. 1999, 18, 223-241. [CrossRef] 
16. McDonald, M.A.; Mathwes, D.M.; Strobel, K.H. Understanding sequence: A tale of two objects. Res. Coll. Math. Educ. 2000, 4, 77-102.

17. Mamona-Downs, J. Letting the intuitive bear on the formal; a didactical approach for the understanding of the limit of a sequence. Educ. Stud. Math. 2001, 48, 259-288. [CrossRef]

18. Roh, K.H. Students' images and their understanding of definition of the limit of a sequence. Educ. Stud. Math. 2008, 69, 217-233. [CrossRef]

19. Arganbright, D. Using Spreadsheets with Mathematically Gifted Students. Res. Math. Educ. 2006, 10, $33-47$.

20. Chappell, K.; Kilpatrick, K. Effect of concept-based instruction on students' conceptual understanding and procedural knowledge of calculus. Primus 2003, 13, 17-37. [CrossRef]

21. Swinyard, C. Reinventing the formal definition of limit: The case of Amy and Mike. J. Math. Behav. 2011, 30, 93-114. [CrossRef]

22. Jones, S.R. Calculus limits involving infinity: The role of students' informal dynamic reasoning. Int. J. Math. Educ. Sci. Technol. 2015, 82, 105-126. [CrossRef]

23. Pinto, M.; Scheiner, T. Making sense of students' sense making: Revisiting the case of Colin through the lenses of the structural abstraction framework. In Proceedings of the INDRUM 2016: First Conference of International Network for Didactic Research in University Mathematics, Montpellier, France, 31 March-2 April 2016; Available online: https://hal.archives-ouvertes.fr/hal-0133 7900 (accessed on 10 December 2020).

24. Fernández-Plaza, J.A.; Simpson, A. Three concepts or one? Students' understanding of basic limit concepts. Educ. Stud. Math. 2016, 93, 315-332. [CrossRef]

25. Bernheim, D.M.; Garrett, D.M.; Maki, D.M. Education and saving: The long-term effects of high school financial curriculum mandates. J. Public Econ. 2001, 80, 435-465. [CrossRef]

26. Avard, S.; Manton, E.; English, D.; Walker, J. The financial knowledge of college freshmen. Coll. Stud. J. 2005, 39, 321-339.

27. OECD. OECD Project on Financial Education and its International Network on Financial; OECD: Paris, France, 2003.

28. Vankúš, P. Implementation of the interactive Microsoft Excel sheets in the teaching of financial literacy. In Sborník Př́ispěvků 5. Konference Užití Počítačů ve Výuce Matematiky; Jihočeská Univerzita České Budějovice: České Budějovice, Czech Republic, 2011; pp. 390-400.

29. Chong, C.-K.; Puteh, M.; Goh, S.-C. Framework to Integrate Spreadsheet into the Teaching and Learning of Financial Mathematics. Electron. J. Math. Technol. 2015, 9, 92-106.

30. Drábeková, J.; Švecová, S. Some notes on the financial literacy of the Slovak students—Case study. MERAA 2015, 2, 68-72. [CrossRef]

31. Fajkus, M. A simple model of an economical problem in the Mathematica environment. Trendy Vzdělávání 2016, 9, 56-62. [CrossRef]

32. Rosaker, K.M.; Rosaker, R.E. An exploratory study of financial literacy training for accounting and business majors. Int. J. Manag. Educ. 2016, 14, 1-7. [CrossRef]

33. Rosa, P.; Petrášková, V. Potential of Maple as a tool for improving financial education of future teachers. Int. J. Technol. Math. Educ. 2017, 24, 161-166.

34. Lopes, A.P.; Soares, F. Perception and performance in a flipped Financial Mathematics classroom. Int. J. Manag. Educ. 2018, 16, 105-113. [CrossRef]

35. Slavíčková, M. Using Graphic Calculus on Calculus lessons. ADUC-M 2009, 9, 109-122.

36. Slavíčková, M. Changes in teaching of calculus at the university level. ADUC-M 2013, 13, $33-45$.

37. Regecová, M.; Slavíčková, M. Financial literacy of graduated students. ADUC-M 2010, 10, 121-147.

38. Regecová, M.; Slavíčková, M. Curricular changes in preparation of future teachers-Financial mathematics course. In Proceedings of the Seventh Congress of the European Society for Research in Mathematics Education, Rzeszów, Poland, 9-13 February 2011; pp. 2808-2816.

39. Papert, S.; Harel, I. Situating Constructionism. In Constructionism; Ablex Publishing Corporation: Norwood, NJ, USA, 1991; Available online: http:/ / www.papert.org/articles/SituatingConstructionism.html (accessed on 8 March 2021).

40. Hoyles, C.; Noss, R. What can digital technologies take from and bring to research in mathematics education? In Second International Handbook of Mathematics Education; Bishop, A.J., Clements, M.A., Keitel, C., Kilpatrick, J., Leung, F.K.S., Eds.; Kluwer: Dordrecht, The Netherlands, 2003; Volume 1, pp. 323-349.

41. Sfard, A. On the dual nature of mathematical conceptions: Reflections on processes and objects as different sides of the same coin. Educ. Stud. Math. 1991, 22, 1-36. [CrossRef]

42. Moschkovich, J.; Schoenfeld, A.H.; Arcavi, A. Aspects of understanding: On multiple perspectives and representations of linear relations and connections among them. In Integrating Research on the Graphical Representation of Functions; Romberg, T.A., Fennema, E., Carpenter, T.P., Eds.; Lawrence Erlbaum: Hillsdale, MI, USA, 1993; pp. 69-100.

43. Dubinsky, E. Reflective abstraction in advanced mathematical thinking. In Advanced Mathematical Thinking; Tall, D., Ed.; Kluwer: Dordrecht, The Netherlands, 1991; pp. 95-123.

44. Gray, E.M.; Tall, D.O. Duality, ambiguity and flexibility in successful mathematical thinking. In Proceedings of the PME XV, Assisi, Italy, 29 June-4 July 1991; Volume II. pp. 72-79.

45. Eisenberg, T.; Dreyfus, T. On visual versus analytical thinking in mathematics. In Proceedings of the 10th PME International Conference, London, UK, 20-25 July 1986; pp. 153-158. 
46. Hillel, J.; Kieran, C. Schemas used by 12-year-olds in solving selected turtle geometry tasks. Rech. Didact. Mathématiques 1987, 8, 61-102.

47. Artigue, M.; Defouad, B.; Duperier, M.; Juge, G.; Lagrange, J.-B. Intégration de Calculatrices Complexes Dans L'enseignement des Mathématiques au Lycée. Cahier de DIDIREM, Numéro Spécial, no. 4; Université Denis Diderot, Équipe DIDIREM: Paris, France, 1998.

48. Trouche, L. Managing the complexity of human/machine interactions in computerized learning environments: Guiding students' command process through instrumental orchestrations. Int. J. Comput. Math. Learn. 2004, 9, 281-307. [CrossRef]

49. Mishra, P.; Koehler, M.J. Technological pedagogical content knowledge: A framework for teacher knowledge. Teach. Coll. Rec. 2006, 108, 1017-1054. [CrossRef]

50. Koehler, M.J.; Mishra, P.; Kereluik, K.; Shin, T.S.; Graham, C.R. The Technological Pedagogical Content Knowledge Framework. In Handbook of Research on Educational Communications and Technology; Spector, J.M., Merril, M., Elen, J., Bishop, M., Eds.; Springer: New York, NY, USA, 2014; Volume 9, pp. 101-111.

51. Artigue, M.; Trouche, L. Revisiting the French didactic tradition through technological lenses. Mathematics 2021, 9, 629. [CrossRef]

52. Ball, D.; Thames, M.; Phelps, G. Content Knowledge for Teaching: What Makes It Special? J. Teach. Educ. 2008, 59, 389-407. [CrossRef]

53. Brousseau, G. Theory of Didactical Situations; Kluwer Academic Publisher: Dordrecht, The Netherlands, 1997.

54. Ernest, P. Reflections on Theories of Learning. In Theories of Mathematics Education. Advances in Mathematics Education; Sriraman, B., English, L., Eds.; Springer: Berlin/Heidelberg, Germany, 2010; pp. 39-47.

55. Dubinsky, E.; McDonald, M.A. APOS: A Constructivist Theory of Learning in Undergraduate Mathematics Education Research. In The Teaching and Learning of Mathematics at University Level; Holton, D., Artigue, M., Kirchgräber, U., Hillel, J., Niss, M., Schoenfeld, A., Eds.; Springer: Dordrecht, The Netherlands, 2001; pp. 275-282.

56. Sierpinska, A. Lecture notes on the Theory of Didactic Situations in mathematics. Lecture 1. Montreal, Canada. 2003. Available online: https:/ / www.academia.edu/27542930/Lecture_notes_on_the_Theory_of_Didactic_Situations_in_mathematics (accessed on 20 February 2021).

57. Swidan, O. How did the indefinte integral function become an accumulation function? In Proceedings of the 35th Conference of the Internatinoal Group for the Psychology of Mathematics Education, Ankara, Turkey, 10-15 July 2011; Volume 4, pp. 233-240.

58. Hitt, F.; González-Martín, A.S. Generalization, covariation, functions, and Calculus. In Second Handbook of Research on the Psychology of Mathematics Education. The Journey Continues; Gutiérrez, A., Leder, G.L., Boero, P., Eds.; Sense Publishers: Rotterdam, The Netherlands, 2016; pp. 3-38.

59. Connors, M.A.; Snook, K. The effects of hand-held CAS on students achievement in a first year college core calculus sequence. Int. J. Comput. Algebra Math. Educ. 2011, 8, 99-114.

60. Crocker, D.A. Development of a concept of derivative in a calculus class using the computer algebra system Mathematica. In Proceedings of the 4th Annual International Conference on Technology in Collegiate Mathematics, Portland, Oregon, 15-17 November 1991; Reading, MA: Addison Wesley, 1993. pp. 251-255.

61. Tall, D.; Vinner, S. Concept image and concept definition in mathematics with particular reference to limits and continuity. Educ. Stud. Math. 1981, 12, 151-169. [CrossRef]

62. Artigue, M. Cognitive difficulties and teaching practices. In The Concept of Function: Aspects of Epistemology and Pedagogy; Harel, G., Dubinsky, E., Eds.; The Mathematical Association of America: Washington, DC, USA, 1992; pp. 109-132.

63. Williams, S.R. Predications of the limit concept: An application of repertory grids. J. Res. Math. Educ. 2001, 32, 341-367. [CrossRef]

64. Slavíčková, M. Developing conceptual knowledge by using ICT on mathematics lessons. In Proceedings of the Tenth Congress of the European Society for Research in Mathematics Education, Dublin, Ireland, 1-5 February 2017; pp. $2314-2315$.

65. Vargová, M.; Slavíčková, M. Geometrical perspective as the introduction into limit process. In Proceedings of the Aplimat 2019: 18th Conference on Applied Mathematics, Slovenská Technická Univerzita v Bratislave, Bratislava, Slovakia, 5-7 February 2019; pp. 1291-1301.

66. Vargová, M.; Slavíčková, M. Students' misconceptions in definition of a limit of sequence. In Proceedings of the Aplimat 2020: 19th Conference on Applied Mathematics, Spektrum STU, Bratislava, Slovakia, 4-6 February 2020; pp. 1089-1097.

67. Blokland, P. Visual Understanding-Educational Software for Math. Available online: https://www.vusoft.eu/ (accessed on 2 March 2021).

68. Sierpinska, A. Humanities students and epistemological obstacles related to limits. Educ. Stud. Math. 1987, 18, 371-397. [CrossRef]

69. Tall, D. Natural and Formal Infinites. Educ. Stud. Math. 1991, 48, 199-238. [CrossRef]

70. Slavíčková, M. Experimental teaching of arithmetic by using computers. In Proceedings of the ICME 11 Topic Study Group 10: Research and Development in the Teaching and Learning of Number Systems and Arithmetic, Monterrey, Mexico, 6-13 July 2008; University of Leuven: Leuven, Belgium, 2008; pp. 103-111.

71. Jonassen, D.H. Computers as Mindtools for Schools; Prentice Hall: Hoboken, NJ, USA, 2000.

72. Perrin-Glorian, M.-J. Questions didactiques soulevées à partir de l'enseignement des mathématiques dans des classes "faibles". Rech. Didact. Mathématiques 1993, 13, 5-118.

73. Gras, R. Data Analysis: A Method for the Processing of Didactic Questions. In Research in Didactique of Mathematics: Selected Papers; Douady, R., Mercier, A., Eds.; La Pensée Sauvage Éditions: Grenoble, France, 1992; pp. 93-106.

74. Carraher, D.W.; Schliemann, A.D. Is everyday mathematics truly relevant to mathematics education? J. Res. Math. Educ. 2002, 11, 131-153. [CrossRef] 
75. Slavíčková, M.; Regecová, M. Does students' everyday experiences influence their mathematical thinking? (Focused on financial mathematics). In Proceedings of the ICERI 2018: 11th Annual International Conference of Education, Research and Innovation, Seville, Spain, 12-14 November 2018; pp. 3417-3423.

76. Anderson, L.W.; Krathwohl, D.R. A Taxonomy for Learning, Teaching, and Assessing: A Revision of Bloom's Taxonomy of Educational Objectives; Longman: New York, NY, USA, 2001.

77. Slavíčková, M.; Vargová, M. Secondary mathematics misconception as a main obstacle in solving higher mathematics problems. In Proceedings of the ICERI 2018: 11th Annual International Conference of Education, Research and Innovation, Seville, Spain, 12-14 November 2018; pp. 965-971.

78. Ndlovu, M.; Ramdhany, V.; Spangenberg, E.D.; Govender, R. Preservice teachers' beliefs and intentions about integrating mathematics teaching and learning ICTs in their classrooms. ZDM Math. Educ. 2020, 52, 1365-1380. [CrossRef]

79. Kendal, M.; Stacey, K. The Impact of Teacher Privileging on Learning Differentiation with Technology. Int. J. Comput. Math. Learn. 2001, 6, 143-165. [CrossRef]

80. Drijvers, P.; Doorman, M.; Boon, P.; Reed, H.; Gravemeijer, K. The teacher and the tool: Instrumental orchestrations in the technology-rich mathematics classroom. Educ. Stud. Math. 2010, 75, 213-234. [CrossRef]

81. Ferrara, F.; Pratt, D.; Robutti, O. The role and uses of technologies for the teaching of algebra and calculus. In Handbook of Research on the Psychology of Mathematics Education: Past-Present-Future; Gutiérrez, A., Boero, P., Eds.; Sense Publishers: Rotterdam, The Netherlands, 2006; pp. 237-273.

82. Petrášková, V.; Hašek, R. Cesta ke zvyšování fi nanční gramotnosti budoucích učitelů. e-Pedagogium 2009, 5, 86-105.

83. Sawang, S.; O'Connor, P.; Ali, M. IEngage: Using technology to enhance students' engagement in a large classroom. J. Learn. Des. 2017, 10, 11-19. [CrossRef] 